\title{
Two modes of inhibitory neuronal shutdown distinctly amplify seizures in humans
}

\section{AUTHORS}

Omar J. Ahmed 1,2,3,4,5,14,15,\#, Tibin T. John ${ }^{1,2,15}$, Shyam K. Sudhakar ${ }^{1}$, Ellen K.W. Brennan ${ }^{1,2}$,

Alcides Lorenzo Gonzalez ${ }^{1,2}$, Jason S. Naftulin ${ }^{8}$, Emad Eskandar ${ }^{9}$, Joseph R. Madsen ${ }^{10}, \mathrm{G}$.

Rees Cosgrove ${ }^{11}$, Andrew S. Blum ${ }^{12}$, N. Stevenson Potter ${ }^{12}$, George A. Mashour,7, Leigh R.

\section{AFFILIATIONS}

${ }^{1}$ Dept. of Psychology,

${ }^{2}$ Neuroscience Graduate Program,

${ }^{3}$ Michigan Center for Integrative Research in Critical Care,

${ }^{4}$ Kresge Hearing Research Institute,

${ }^{5}$ Dept. of Biomedical Engineering,

${ }^{6}$ Dept. of Anesthesiology,

${ }^{7}$ Dept. of Neurosurgery,

University of Michigan, Ann Arbor, MI 48109.

${ }^{8}$ Dept. of Neurology,

${ }^{9}$ Dept. of Neurosurgery,

Harvard Medical School and Massachusetts General Hospital, Boston, MA 02114

${ }^{10}$ Dept. of Neurosurgery,

Boston Children's Hospital, Boston, MA 02115

${ }^{11}$ Dept. of Neurosurgery,

Harvard Medical School and Brigham and Women's Hospital, Boston, MA 02115

${ }^{12}$ Dept. of Neurology,

Rhode Island Hospital, Providence, RI 02903

${ }^{13}$ School of Engineering, Brown University, Providence, RI 02912

${ }^{14}$ Co-senior authors

${ }^{15}$ Co-first authors

\section{\#LEAD CONTACT \& CORRESPONDING AUTHOR}

Omar J. Ahmed

Mail: Department of Psychology, 530 Church St. University of Michigan, Ann Arbor, MI 48109 Email: ojahmed@umich.edu

KEYWORDS: inhibition, excitation, epilepsy, temporal lobe, mesial temporal sclerosis,

\section{Page 1}




\section{ABSTRACT}

58 Inhibitory neurons are critical for normal brain function but dysregulated in disorders

59 such as epilepsy. At least two theories exist for how inhibition may acutely decrease

60 during a seizure: hyperpolarization of fast-spiking (FS) inhibitory neurons by other

61 inhibitory neurons, or depolarization block (DB) of FS neurons resulting in an inability to

62 fire action potentials. Firing rate alone is unable to disambiguate these alternatives.

63 Here, we show that human FS neurons can stop firing due to both hyperpolarization and

64 DB within the same seizure. However, only DB of FS cells is associated with dramatic

65 increases in local seizure amplitude, unobstructed traveling waves, and transient

66 increases in excitatory neuronal firing. This result is independent of seizure etiology or

67 focus. Computational models of DB reproduce the in vivo human biophysics. These

68 methods enable intracellular decoding using only extracellular recordings in humans

69 and explain the otherwise ambiguous inhibitory neuronal control of human seizures. 


\section{INTRODUCTION}

Epilepsy is a debilitating disease affecting some 50 million people worldwide ${ }^{1,2}$. Epileptic

91 seizures are thought to result from an imbalance between excitatory and inhibitory

92 neuronal activity ${ }^{3}$. However, electrographically similar seizures on the macroscopic

93 scale can be driven by mechanistically distinct processes on the cellular and cell-type

94 population scale ${ }^{4}$. Thus, the relative roles of local inhibitory and excitatory networks in

95 driving seizure progression must be elucidated to guide the development of novel

96 treatments for intractable epilepsies and our understanding of their associated seizures.

97 Due to the tremendous technical challenges of recording from individual human neurons

98 and the relative sparsity of inhibitory neurons, the activity of well isolated inhibitory

99 interneurons during seizures is only rarely examined ${ }^{5,6}$.

101 There are several theories, based on slice and whole animal experiments, proposing

102 both insufficient ${ }^{7-15}$ and excessive ${ }^{16-20}$ inhibition as possible facilitators of epileptic

103 activity, with at least two hypotheses for how inhibition may acutely decrease during a

104 seizure: (1) hyperpolarization of fast-spiking (FS) inhibitory neurons by other inhibitory

105 neurons ${ }^{21-24}$, or (2) excessive depolarization of FS neurons that precludes subsequent

106 action potentials due to blockade of voltage-dependent sodium channels ${ }^{12,14,25,56}$.

107 Resolving these two theories necessitates whole cell recordings ${ }^{26}$, but it is practically

108 impossible to record the intracellular membrane potential of neurons during human

109 seizures in vivo. In this study, we address these challenges by combining (1) large-

110 scale extracellular recordings of human neocortical inhibitory and excitatory neurons

111 during focal seizures with secondary generalization and (2) a novel method of decoding 
medRxiv preprint doi: https://doi.org/10.1101/2020.10.09.20204206; this version posted October 20, 2020. The copyright holder for this preprint (which was not certified by peer review) is the author/funder, who has granted medRxiv a license to display the preprint in perpetuity.

112 membrane potential trajectory from extracellular action potentials. We show the

113 remarkable ability of active fast-spiking inhibitory neurons to block epileptic traveling

114 waves in human neocortex, and reveal the dynamical control of human seizures by the

115 subthreshold trajectory of inhibitory neurons.

116

117 


\section{RESULTS}

119 Patients were implanted with intracranial grid electrodes as part of the clinical process

120 of identifying the precise site of origin of their drug-resistant focal epilepsy (see

121 Materials and Methods). A 4x4 mm NeuroPort microarray (Blackrock Microsystems)

122 was also placed in a region of the neocortex that was expected to be in the resection

123 site (Figure 1a; Extended Data Fig. 1a). Histology of the resected tissue confirmed that

124 the electrodes consistently targeted layers 2/3 of the neocortex (Extended Data Fig. 1b).

125 We used these arrays to simultaneously record the activity of dozens of individual

126 neocortical neurons during both ictal and interictal activity. We then classified the

127 neurons as either fast-spiking (FS) inhibitory interneurons or regular-spiking (RS)

128 excitatory cells using well-established criteria $^{27,28}$, including action potential shape

129 (Extended Data Fig. 1C-f). FS cells correspond to the class of parvalbumin-expressing

130 interneurons and represent the largest source of inhibition in the neocortex ${ }^{29}$. The

131 resulting information thus allowed us to differentiate between putative inhibitory and

132 excitatory unit activity patterns during seizure progression in humans.

134 A total of 37 FS cells and 539 RS cells were recorded across 4 patients with NeuroPort

135 arrays implanted in the temporal neocortex (see Supplementary Methods for details

136 about each patient). As secondarily generalized seizures first reached the arrays, both

137 FS and RS cells increased their rate of action potentials (Figs. 1, 2, and Extended Data

138 Figs. 2-4). This finding is consistent with what is known about the feedforward

139 recruitment of both inhibition and excitation ${ }^{25,30}$. At the population level, the FS firing

140 rate was significantly higher than RS cells $(100,000$ bootstrap iterations of label-shuffled 
141 peak rate differences; $p=0.036)$. Within 40 seconds of seizure onset, the mean FS firing

142 rate fell rapidly to $0-2 \mathrm{~Hz}$ at the same time as local field potential intensity increased

143 dramatically to its highest levels (Figs. 1, 2, and Extended Data Figs. 2-4). Consistently,

144 among the best isolated FS units during the seizure (isolation quality discussed in more

145 detail below and see Methods), 10 out of 15 had at least one nearby RS cell that

146 exhibited the peak of its overall activity several seconds after the dramatic fall in local

147 FS activity and accompanying elevation in local field potential intensity (Figs. 1, 2, and

148 Extended Data Figs. 2-4). Thus, at the population level, FS cells show a cessation of

149 activity near the middle of secondarily generalized seizures accompanied by a dramatic

150 increase in the amplitude of seizure activity. This FS cessation is followed by a transient

151 increase in RS cell firing, presumably because these RS cells are now less inhibited

152 due to the loss of FS firing. The RS population rate eventually also fell to an average of

$153 \quad 0-3 \mathrm{~Hz}$ but with a delay of several seconds following FS cells. At the population level,

154 FS cells $(\mathrm{N}=37)$ exhibited significantly earlier cessation times than $\mathrm{RS}$ cells $(\mathrm{N}=539)$

155 (Fig. 2g-j, FS cell average cessation occurred 4.6 seconds earlier than RS average

156 cessation; 100,000 bootstrap iterations of label-shuffled time differences; $p<0.0001)$.

158 We next compared activity patterns among individual FS cells. Many individual FS cells

159 did not start firing until $\sim 10$ seconds into the seizure, often starting to fire robustly only

160 after the RS rate had already increased (Figs. 1, 2, and Extended Data Figs. 2-4). As

161 seen with the population means (Fig. 2g), each individual FS cell dramatically reduced

162 its firing roughly half-way through the seizure (Figs. 1, 2, and Extended Data Figs. 2-4).

163 However, even simultaneously recorded FS cells during a single seizure did not 
164 necessarily cease firing at the same time, just as they did not start firing at the same

165 time. Figure 1 shows the activity of two simultaneously recorded FS cells that were

166 separated by a distance of $2.04 \mathrm{~mm}$. FS Cell 1 (Fig. 1a) approached cessation $\sim 35$

167 seconds into the seizure, and at $\sim 35$ seconds, the amplitude of the LFP next to FS Cell

1681 increased dramatically, as did the firing rate of nearby RS cells. FS Cell 2 (Fig. 1b)

169 approached cessation 24 seconds into the seizure, and the LFP amplitude next to FS

170 Cell 2 also increased at $\sim 24$ seconds, along with the firing rate of nearby RS cells.

171 Furthermore, when sorting all simultaneously recorded channels during a seizure by the

172 timing of transition to the large amplitude spike-and-wave event phase, a raster plot of

173 all spikes with units sorted in the same order produced a similar sequence of mid-

174 seizure firing time cessations (Fig. 1c\&d). Thus, FS cell cessation is correlated with a

175 dramatic increase in the very local intensity of seizures.

177 Given changing waveform shapes and noise characteristics during seizures ${ }^{31}$, an

178 important methodological question arises of how separable clusters in waveform feature

179 space are from each other and from noise to allow valid unit assignments during this

180 period. To quantitatively assess this isolation quality of feature space clusters over the

181 course of seizures, we employed a modified version of the Lratio metric of cluster

182 separation introduced and validated by Schmitzer-Torbert et al. (2005) ${ }^{58}$ (see Methods).

183 Cluster divisions with Lratio less than 0.1 are considered to have a significantly low level

184 of false negative contamination, indicating that drops in firing rate are not caused by

185 over-assigning candidate spikes to noise or other clusters due to changing waveform

186 shapes in these divisions. We consider units whose average contamination level across 
medRxiv preprint doi: https://doi.org/10.1101/2020.10.09.20204206; this version posted October 20, 2020. The copyright holder for this preprint (which was not certified by peer review) is the author/funder, who has granted medRxiv a license to display the preprint in perpetuity.

It is made available under a CC-BY-NC-ND 4.0 International license .

187 seizure divisions (dynamic Lratio ) is less than 0.1 to be a best-isolated subset ${ }^{58}$. Figure 2

188 shows an example of an FS unit whose waveform shape could be well isolated from

189 noise across the entire seizure despite showing a monotonic decrease in spike

190 amplitude (Fig. 2a-c). The isolation quality of this unit throughout the seizure is

191 demonstrated visually by 2D voltage histograms of these waveforms (Fig. $2 \mathrm{~d}$ ) and is

192 quantitatively captured by its dynamic Lratio being far below threshold in all seizure

193 divisions in which it was active (Fig. 2b). This isolation quality was similarly sustainable

194 throughout the seizure for many RS units (e.g. Extended Data Fig. 5), although at a

195 lower proportion than FS units, with $48.6 \%$ of FS units meeting this criterion but only

$19619.8 \%$ of RS units. This pattern sustained throughout seizures, with the proportion of

197 well-isolated FS units remaining between $30 \%$ and $48 \%$ across all 8 seizure divisions

198 and that of RS units remaining between 13\% and 19\% (Extended Data Fig. 6). The

199 apparent difference in sortability by cell type may be because the frequency content of

200 noise is such that random threshold crossings are more similar in shape and amplitude

201 to the wider waveforms of RS units than to the sharper waveforms of FS units. This

202 suggests that FS cell spikes are inherently more distinguishable from noise in human

203 neocortical recordings even during seizures. We considered the best-isolated subset of

204 units following this quantitative criterion in parallel with all-inclusive analyses of firing

205 rate dynamics in various time divisions of seizures with similar results. In particular,

206 similar temporal profiles by cell type were observed throughout seizures when

207 considering all units or only best-sorted units with an average Lratio $<0.1$ across all

208 divisions for Patient C (Fig. 2e\&f), as well as when comparing average firing rate time

209 courses by cell type across all patients (Fig. 2g\&h). Furthermore, the observed time 
210 difference between mean RS activity cessation timing and mean FS activity cessation

211 timing remained significantly larger than that expected by random cell-type label

212 reshuffling when considering all units $(\mathrm{p}<0.0001$; Fig. $2 \mathrm{i})$, as well as only best-isolated

213 units with maximum Lratio $<0.1(p<0.005$; Fig. 2j). Thus, FS cell cessation occurs several

214 seconds before RS cell cessation across the population as well as for the very best

215 isolated units.

217 The firing profile of individual FS cells and the accompanying changes in the seizure

218 LFP amplitude were remarkably consistent across all secondary generalized focal

219 seizures examined, independent of etiology or focus (Figs. 1, 2, and Extended Data

220 Figs. 2-4). In patients with an etiology of mesial temporal sclerosis, where the seizure

221 started focally in the hippocampus or surrounding medial temporal regions, FS cells in

222 the temporal neocortex consistently stopped firing after the seizure secondarily

223 generalized and spread to the neocortex, leading to accompanying increases in seizure

224 LFP amplitude (Fig. 1a\&b). Similarly, in a patient with an etiology of neocortical

225 dysplasia (Patient C) where the seizure originated in the temporal neocortex, several

$226 \mathrm{~cm}$ from the implanted electrode array, FS cells near the array stopped firing within the

227 first 40 seconds of the seizure spreading to that location (Fig. 2a\&b). Again, this

228 coincided with a transition to even larger amplitude spike-wave LFP events.

230 The variability in FS cessation times raises the question of how seizure waves travel

231 across the neocortex: is there a wave that slowly moves across the cortex ${ }^{32}$ or a series

232 of faster waves that are perhaps altered by the local activity of FS cells ${ }^{11,30,33}$ ? We found 
233 fast traveling LFP waves in all patients that swept across the $4 \times 4 \mathrm{~mm}$ microelectrode

234 array within $40 \mathrm{~ms}$, at a speed of $\sim 0.1 \mathrm{~m} / \mathrm{s}$, consistent with estimates from slice and

235 computational studies ${ }^{30,34-36}$. There was a dramatic effect of individual FS cell activity:

236 when an FS cell was still firing, it was able to impede and alter epileptic traveling waves

237 (Fig. 3a), preventing the wave from increasing the seizure's LFP amplitude in the vicinity

238 of the FS cell. Once the FS cell activity ceased, traveling waves swept through the

239 entire array, successfully recruiting the area around the now-silent FS cell (Figure 3B).

240 Indeed, once all FS cells had switched off, the path of epileptic traveling waves became

241 far more regular and stereotyped. Thus, human FS inhibitory cells possess a

242 remarkable capability to obstruct and alter the path of epileptic traveling waves. This

243 again points to the importance of FS activity in controlling local neuronal activity and

244 LFP dynamics during local seizure propagation but leaves open the question of what is

245 causing them to stop firing during the seizure.

247 There are two ways in which FS cells can stop firing during a seizure: 1) they could be

248 hyperpolarized by inhibition from other inhibitory neurons ${ }^{22}$, also known as the

249 disinhibition hypothesis ${ }^{23}$; or 2) they could enter depolarization block and thus become

250 incapable of firing additional action potentials, despite receiving strong excitatory

251 synaptic input ${ }^{12,14,25,56}$. These two scenarios produce very different predictions for how

252 the action potential (AP) amplitude of an FS cell should change during a seizure. In the

253 case of hyperpolarization, the AP amplitude should increase as the firing rate is

254 decreasing. In the case of depolarization block, AP amplitude should decrease before

255 the cell stops firing while its firing rate is also decreasing. To monitor the relative 
256 contributions of hyperpolarization and excessive depolarization throughout the seizure

257 in each recorded unit, we therefore devised a novel method that decodes the

258 membrane potential regime of neurons from extracellular spike amplitude data by

259 computing the sign of the correlation between AP amplitude and firing rate in each

260 second of the seizure (Fig. 4a-c; see Methods). Some units first paused their firing due

261 to transient inhibition from other cells, as suggested by strongly negative correlations

262 between AP amplitude and firing rate as firing rate initially decreased (Fig. 4b\&h;

263 Extended Data Figs. 7\&8). This period corresponded precisely to the time period of

264 increased firing in neighboring FS units (Fig. 4d\&j). However, these apparently

265 hyperpolarized units resumed their firing after this pause. Cessation of firing

266 subsequently occurred presumably due to massive depolarization of their membrane

267 potential, as demonstrated by strongly positive correlations of AP amplitude and firing

268 rate as these units stopped firing spikes (Fig. 4b\&h). The regimes of negative

269 correlation correspond to a dynamic inhibitory control of local firing rates during the

270 seizure, followed by a regime of positive correlation with decreasing AP amplitudes

271 during the final descent in firing rate, a pattern consistent with what is seen during

272 depolarization block.

273

274 This pattern was also seen on the population level in spiking event-triggered averages

275 of the time course of our predicted membrane potential measure (Fig. 4e). Aligning

276 inferred membrane potential time courses around the time of firing rate pauses

277 (dropping below $30 \%$ of peak rate) revealed a large negative deflection for FS cells,

278 indicative of these units being inhibited via hyperpolarization to reduce firing rate at this 
279 time (Fig. 4e; $n=12 ; R_{\text {mean,pause }}=-0.44 \pm 0.19$ [sem]; less than 0 with $p<10^{-7}$ by bootstrap

280 mean resampling test, $\left.\mathrm{n}_{\text {sample }}=10, \mathrm{~N}_{\text {bootstrap }}=50,000\right)$. Furthermore, the inferred

281 membrane potential amongst the FS cell population showed that this shift was also

282 widespread (Fig. 4f), with 9 out of 12 (75\%) FS units pausing during the negative,

283 hyperpolarized regime during this rate-based event. Aligning inferred membrane

284 potential time courses around the later time of firing rate cessation in units (defined by

285 rate falling below $30 \%$ of peak rate for the final time) revealed a large positive deflection

286 for FS cells, indicative of these units entering a regime depolarization block (Fig. 4e;

$287 \mathrm{n}=26$; $\mathrm{R}_{\text {mean,cess }}=+0.45 \pm 0.12$ [sem]; greater than 0 with $\mathrm{p}<10^{-7}$ by bootstrap mean

288 resampling test, $\left.\mathrm{n}_{\text {sample }}=20, \mathrm{~N}_{\text {bootstrap }}=50,000\right)$. Again, the inferred membrane potential

289 amongst the FS cell population showed that this shift was also widespread across units

290 (Fig. 4f), with 20 out of 26 (77\%) FS units landing in the positive, over-excited regime.

291 When comparing these values only in units that showed both a pause and cessation to

292 control of heterogeneity amongst different units, the inferred membrane potential was

293 still significantly higher as the unit ceased firing compared to as the unit paused its firing

294 (right-sided Wilcoxon signed rank test; $n=12, p=0.0049$ ). Finally, these firing rate

295 descents in FS cell activity were associated with distinct changes in LFP amplitude

296 despite being of the same magnitude (at 30\% of peak firing rate) as shown by event-

297 triggered averages in LFP amplitude (Fig. 4e). FS cessation was associated with a

298 larger LFP amplitude than that associated with pausing even amongst cells exhibiting

299 both events (right-sided Wilcoxon signed rank test; $n=12, p<10^{-4}$ ). Similar results were

300 obtained indicative of significant and widespread overexcitation underlying the cessation

301 of activity in RS units, with 225 out of $331(68 \%)$ RS units with sufficient rate at the time 
302 of cessation exhibiting a positive value (Extended Data Fig. 7e; n=331;

$303 \mathrm{R}_{\text {mean,cess }}=0.30 \pm 0.03$ [sem]; greater than 0 with $p<10^{-7}$ by bootstrap mean resampling

304 test, $\left.\mathrm{n}_{\text {sample }}=20, \mathrm{~N}_{\text {bootstrap }}=50,000\right)$. However, amongst RS cells exhibiting a pause in

305 activity, membrane potential appeared much more heterogenous despite controlling for

306 firing rate at this time, appearing in a bimodal distribution amongst both inhibition and

307 depolarization block that was not significantly different from 0 (Extended Data Fig. 7e\&f;

$308 \mathrm{n}=130 ; R_{\text {mean,cess }}=-0.08 \pm 0.06$ [sem]; greater than 0 with $p=0.3782, n_{\text {sample }}=10$,

$309 N_{\text {bootstrap }}=50,000$ ). This may be because RS cells receive a greater diversity of input

310 magnitudes during seizure progression than do FS cells but succumb to the same, more

311 uniform mechanism underlying depolarization block at firing rate cessation and seizure

312 transition, which we hypothesize is due to increasing potassium concentrations in the

313 extracellular environment shared by all of these cells.

315 This sequence of significant hyperpolarization in FS cells followed by large and

316 widespread overexcitation in all cells suggests a consistent membrane potential-based

317 mechanism by which local cortical circuits fight but ultimately succumb to seizure

318 progression. The dynamics in firing rate and action potential amplitude that characterize

319 this mechanism were accurately reproduced in a computational model of the cell

320 membrane incorporating voltage-dependent sodium and potassium conductances

321 (Hodgkin-Huxley formalism) with stochastic background synaptic input. The model

322 reproduced all of the observed mutual dynamics between action potential rate and

323 amplitude during inhibitory (hyperpolarizing) pauses versus depolarization-induced 
medRxiv preprint doi: https://doi.org/10.1101/2020.10.09.20204206; this version posted October 20, 2020. The copyright holder for this preprint (which was not certified by peer review) is the author/funder, who has granted medRxiv a license to display the preprint in perpetuity.

324 cessation (Fig. 5), confirming the plausibility of this mechanistic sequence driving unit 325 activity patterns during seizure progression.

326

327 


\section{DISCUSSION}

329 We have shown that both FS and RS cells are strongly activated during the initial

330 spread of secondarily generalized seizures. The immediate increase in RS rate at

331 seizure onset, in particular, clearly indicates spread of the seizure, and not a failed

332 seizure in what has been called an ictal penumbra, where no initial increases in RS rate

333 appear ${ }^{32}$. Importantly, we have shown that both FS and RS cells can sometimes pause

334 their activity due to hyperpolarization (likely due to inhibition-mediated hyperpolarization

335 from other nearby inhibitory neurons) but stop firing midway through secondarily

336 generalized seizures due to depolarization block. This result is independent of seizure

337 etiology (cortical dysplasia vs. mesial temporal sclerosis) or site of origin (hippocampus

338 vs. neocortex). This suggests that there is an almost complete lack of FS-mediated

339 inhibition towards the end of a human seizure, in contrast to some animal models

340 without loss of inhibition ${ }^{18}$. FS cells are active near the beginning and middle of the

341 seizure, in contrast to computational models placing the loss of inhibitory restraint at

342 seizure onset ${ }^{37}$. Strikingly, this absence of FS inhibitory activity is accompanied by large

343 increases in the amplitude of the seizure's LFP and unimpeded fast traveling waves, as

344 well as a short-lasting increase in RS firing. Thus, these results suggest a more

345 complicated set of dynamics than a monotonic increase or decrease of inhibition and

346 provide further insight into the associated biophysical mechanisms.

348 The main difference between RS and FS cell firing during the seizures observed here

349 was the significantly earlier cessation of spiking by FS cells, which is consistent with

350 previous results from in vitro models of seizure-like events showing increased 
351 propensity of FS cells to enter depolarization block compared to pyramidal cells ${ }^{12,14,25}$.

352 The reason for this difference in propensity to enter depolarization block has not been

353 established, but these results suggest this difference could represent a primary source

354 of imbalance between excitatory and inhibitory cell activities that allows seizures to

355 propagate and transition to a large amplitude phase in human neocortex. One

356 hypothesis accounting for this difference is that of the differential expression of voltage-

357 gated potassium channel units in FS as opposed to RS cells ${ }^{38-40}$ in combination with the

358 elevated extracellular potassium ion levels known to occur in the context of

359 seizures ${ }^{41,42}$. However, there are several intrinsic and network-based properties that are

360 known to differ between FS cells and pyramidal cells and could contribute to this

361 difference, such as intrinsic excitability and the relative strength of feedforward drive ${ }^{43-}$

36246 . The results here suggest that properties responsible for increasing the propensity of

363 FS cells to enter depolarization block relative to RS cells are also those that allow the

364 propagation and exacerbation of seizures in human neocortex. Beyond seizure

365 progression, it is also possible that the lack of FS activity sets in motion a critical

366 network-level transition that leads to seizure termination ${ }^{47-49}$. This transition may include

367 the activation of inhibitory cell types other than FS cells ${ }^{22,59}$.

369 In summary, FS cells are the largest source of inhibition in the neocortex, and human

370 FS cells approach cessation less than halfway through a seizure, most likely due to

371 depolarization block. This is associated with a dramatic increase of the seizure's local

372 field potential amplitude and a transition to clear spike-and-wave events at a frequency

373 of $\sim 3 \mathrm{~Hz}$. Rhythmic spike-and-wave discharges, when they occur in the motor cortex, 
374 are responsible for the rhythmic $\sim 3 \mathrm{~Hz}$ movements seen during the clonic phase of

375 tonic-clonic seizures ${ }^{50}$. Importantly, this suggests a novel, FS-dependent, mechanistic

376 explanation for the two behaviorally defined phases of secondarily generalized tonic-

377 clonic seizures: the high-FS-rate, low-LFP-amplitude phase of the seizure corresponds

378 to the tonic phase, whereas the post-FS-cessation phase with periodic spike-wave

379 bursts corresponds to a longer lasting clonic phase. Thus, in addition to existing

380 approaches ${ }^{51-55}$, novel therapies that prevent FS cells from entering depolarization

381 block may prevent - or at least limit the severity of - seizures, representing a novel and

382 potentially powerful avenue for treating seizures with many different etiologies. 
METHODS

386 Patients \& Clinical/Research Electrode Placement

387 Approval for all experiments was granted by the Institutional Review Boards of

388 Massachusetts General Hospital / Brigham \& Women's Hospital and Rhode Island

389 Hospital. The decision to implant intracranial electrodes in an epilepsy patient as well

390 the positioning of those electrodes in a patient was made solely on clinical factors by

391 clinical staff. The explicit goal of this study was to examine the single neuron correlates

392 of tonic-clonic seizures ${ }^{42}$ with focal onsets (also referred to as focal seizures with

393 secondary generalization), one of the most common kind of epilepsies ${ }^{56}$. These focal

394 seizures have a localized onset zone, either in the mesial temporal lobe or neocortex,

395 but secondarily generalize, spreading to both hemispheres and almost always leading

396 to impaired consciousness. Here, we studied data from 4 patients (Patients $A, B, C, D$ )

397 with clear focal seizures with secondary generalization, with each of these clinical

398 seizures showing clear spike-and-wave patterns. Two additional patients with temporal-

399 lobe epilepsy were implanted with NeuroPort Arrays but not studied here because one

400 of them did not have any seizures while implanted (Patient E), and the NeuroPort Array

401 in the other patient did not sample any typical spike-and-wave seizures (Patient F). A

402 total of 10 secondarily generalized seizures with spike-and-wave discharges from the 4

403 patients were analyzed (3 each from Patients A and D; 2 each from Patients B and C).

404 A detailed clinical description of each of these 4 patients follows:

405 Patient A. Patient A was a left-handed man in his 30s at the time of his surgery. He had

406 suffered from pharmacologically intractable partial complex seizures for almost two

407 decades. His seizures lasted 1-2 minutes and were characterized by a sudden onset of 
408 slurred and nonsensical speech. This was followed by a staring spell, lack of

409 responsiveness, and head turning to the right. He also displayed automatisms and

410 posturing that involved his right arm and hand more than his left. MRI suggested left

411 (dominant) temporal polymicrogyria. He underwent placement of grids and strips for $\sim 2$

412 weeks to delineate the seizure focus with respect to this area of abnormal sulcation. A

$4134 \times 4 \mathrm{~mm}$ NeuroPort array with $1.5 \mathrm{~mm}$ long contacts was placed in the left superior

414 temporal gyrus. Seizures were found to emanate from the mesial temporal structures,

415 but during secondary generalization, the seizures spread to the location of the array in

416 the superior temporal gyrus and beyond. The patient underwent a left temporal

417 lobectomy, and histology confirmed that the microarray targeted layer 3. Pathology was

418 consistent with mesial temporal sclerosis.

420 Patient B. Patient B was a right-handed man in his 40s at the time of his surgery, with a

421 history of medically refractory epilepsy. His seizures lasted 1-2 minutes. Clinically, the

422 seizures started with arousal and bilateral arm and leg extension. This was followed by

423 leftward head deviation, left arm flexion, and generalized tonic-clonic activity. He

424 underwent placement of grids, strips, and depths in his right hemisphere. A $4 \times 4 \mathrm{~mm}$

425 NeuroPort array (with $1.5 \mathrm{~mm}$ deep contacts) was placed in the right middle temporal

426 gyrus. During secondary generalization, the seizures spread to the location of the

427 NeuroPort array in the middle temporal gyrus and beyond. The patient underwent a

428 right temporal lobectomy. Histology on the resected tissue confirmed that the microarray

429 targeted layer 3. 
431 Patient C. Patient C was a left-handed woman in her 20s at the time of her surgery.

432 She started to have complex partial seizures at least 10 years prior to surgery. These

433 seizures included an aura of nausea and a 'tunneling' sensation, then a flattening of

434 affect, slowed responsiveness, automatisms, and associated amnesia. Such seizures

435 occurred 3-4 times per month and were persistent despite being on a three-drug

436 anticonvulsant regimen. MRI revealed an extensive nodular gray matter heterotopia in

437 the right hemisphere. Video-EEG monitoring had found right hemispheric onset

438 seizures, and fMRI had shown normal left sided language activation patterns and

439 normal motor activation patterns. Wada testing confirmed left hemispheric language

440 dominance and suggested her left hemisphere could adequately support memory

441 function subsequent to a right temporal lobectomy. Based on these data, she was

442 implanted with a combination of subdural grid and strip electrodes over the right

443 hemisphere and 3 depth electrodes into the right temporal lobe. The NeuroPort array

444 (with $1.5 \mathrm{~mm}$ deep contacts) was placed in the right middle temporal gyrus. Her

445 seizures lasted between 1-2.5 minutes. These showed very consistent patterns of

446 seizure onset and propagation on ECoG; all began in the right middle and upper gyri of

447 the posterior temporal cortex. Low amplitude and fast activity were recorded from these

448 grid sites at the onset, followed by a buildup of $11-13 \mathrm{~Hz}$ activities from these leads

449 which then spread anteriorly and inferiorly along the grid. Rhythmic spike-wave

450 discharges were also detected soon after seizure onset spreading to several locations,

451 including the location of the NeuroPort array in the right middle temporal gyrus. The

452 patient underwent an extensive right temporal resection with extension posteriorly

453 toward the right temporo-occipital junction but sparing of much of the mesial temporal 
454 structures (including the hippocampus). Histology confirmed that the array targeted

455 layers 2/3. Pathology revealed subtle neuronal dysgenesis and focal superficial gliosis

456 and encephalomalacia in the posterior temporal neocortex, including the recorded

457 seizure-onset zone. Anterior temporal cortex showed mild gliosis.

459 Patient D. Patient D was a right-handed man in his 20 s whose seizures began when he 460 was a teenager. His seizures were characterized by a blank stare and oral automatisms 461 accompanied by stiffening and posturing of the right hand. His MRI was unremarkable, 462 but his semiology and phase I EEG recordings suggested a left temporal seizure onset.

463 Consequently, he was implanted with several strip electrodes covering the left frontal 464 and temporal regions. The NeuroPort array (1.0 mm deep contacts) was placed in the 465 middle temporal gyrus about $1-2 \mathrm{~cm}$ posterior to the temporal tip. All of the seizures 466 had similar clinical and electrographic signatures with a left gaze preference at onset

467 followed by tonic and then clonic movements of the right arm. Electrographically, the 468 seizures began with a generalized burst of sharp waves followed by sharp wave com469 plexes that were maximal in mesial temporal leads. The participant underwent a left 470 temporal lobectomy. Histological examination of the tissue revealed mild dysplastic 471 changes in the lateral temporal neocortex and gliosis and moderate neuronal loss in 472 regions $\mathrm{CA} 4$ and $\mathrm{CA} 3$ of the hippocampus.

\section{NeuroPort Recordings, Data Collection \& Analysis}

475 A Neuroport array (manufactured by Blackrock Microsystems) is a $10 \times 10$ grid of 476 electrodes with an inter-electrode spacing of $400 \mathrm{um}$, giving a total size of $4 \times 4 \mathrm{~mm}$. The 
477 depth of the electrodes used in this study was either $1.5 \mathrm{~mm}$ (Patients $A, B, C$ ) or $1.0 \mathrm{~mm}$

478 (Patient D). 96 of the 100 electrodes were used to record the activity of individual

479 neurons as well as the local field potential (LFP). The 0.3-7500 Hz wideband analog

480 signal from each electrode was referenced to a distant intracranial reference wire and

481 sampled at $30 \mathrm{kHz}$. The LFP shown in Figs. 1, 2, and Extended Data Fig. 1 were z-

482 scored, but not filtered any further. Traveling wave analysis \& images (Fig. 3) made use

483 of these z-scored, unfiltered LFP signals. For single unit analysis, the broadband signal

484 was high-pass filtered above $250 \mathrm{~Hz}$ using a 6-pole Bessel filter and then manually

485 spike-sorted using Plexon Offline Sorter. We then classified the neurons as either fast-

486 spiking (FS) inhibitory interneurons or regular-spiking (RS) excitatory cells using well-

487 established criteria $^{27,28}$, including action potential shape. Cessation of firing during a

488 seizure was defined as the bin after which the firing rate never exceeded $30 \%$ of the

489 unit's peak rate. For action-potential (AP) amplitude analysis (Fig. 4a), the AP amplitude

490 was defined as the trough-to-peak amplitude of each individual extracellular action

491 potential.

492

493 Cluster isolation quality assessment: Dynamic LRatio

494 To assess the isolation quality of feature space clusters over the course of seizures, we

495 employed a modified version of the Lratio metric of cluster separation introduced and

496 validated by Schmitzer-Torbert et al. $(2005)^{58}$. This involved first calculating the

497 Mahalanobis distance of every spike to a given cluster's center in a 4D feature space

498 consisting of trough-to-peak amplitude, trough-to-peak width, principal component 1,

499 and principal component 2. The Mahalanobis distance normalizes the Euclidean 
distance by the variance of a given cluster along its major dimensions to correct for correlations amongst features. Schmitzer-Torbert et al. (2005) ${ }^{58}$ showed strong error

502 rate correlation with ground truth extracellular spikes by assuming a multi-dimensional

503 Gaussian distribution for a given cluster and taking the amount of contamination by

504 false negative assignments to be the sum of probabilities of each un-clustered spike of

505 a given Mahalanobis distance to belong to that Gaussian, which was robust to the

506 particular feature space used. These probabilities are given by the inverse of the

507 cumulative distribution function of a chi-squared distribution with degrees of freedom

508 equal to the number of features in the features space, the sum of which is called L.

509 Because clusters in this space moved over the course of the seizure in a non-monotonic

510 pattern here, we calculated Mahalanobis distances to a surrogate cluster for multiple

511 subsets of the whole cluster at 8 equal divisions over the course of the seizure and 3

512 divisions of the 10 minute period that occurred two minutes after the end of the seizure.

513 A composite cluster across initial divisions was used to provide a liberal estimate of the

514 space that a given cluster might occupy despite early waveform shape changes. This

515 composite reference cluster included all available spikes before the seizure along with

516 those in the first two divisions of the seizure, which were generally well-sortable. We

517 calculated the sum of false negative assignment probabilities under a Gaussian model

518 for this reference cluster, the value $\mathrm{L}$, for each seizure and post-seizure division. We

519 then dynamically normalized $L$ by the number of spikes assigned to the cluster in each

520 time division to estimate contamination rates relative to the number of spikes assigned

521 during that division, which we refer to as the dynamic Lratio. 


\section{Membrane potential trajectory analysis}

524 We exploited the biophysical relationship between depolarization, voltage-gated $\mathrm{Na}+$

525 channel inactivation, and spike waveform shape ${ }^{60}$ to infer the direction of membrane

526 potential changes underlying the changes in firing rate exhibited by single units

527 recorded extracellularly in patients across time. This was done for a given unit by first

528 computing the local spike rate and average trough-to-peak waveform amplitude in

529 moving time windows of width 1 second unless otherwise specified, moving with a step

530 size of 0.1 seconds. Then a linear regression was performed at each point in this series

531 across a moving time window of 3 seconds, producing a time series of correlation

532 coefficients for bins with an average spike rate of at least $5 \mathrm{~Hz}$. Strong negative

533 correlations were taken as evidence of firing rate changes associated with membrane

534 potential changes near resting membrane potential, while strong positive correlations

535 were taken as evidence of membrane potential changes closer to firing threshold, near

536 the regime of depolarization block $^{56}$.

\section{Computational model}

539 Computer simulations of transmembrane voltage dynamics consistent with the

540 extracellular observations here were made in MATLAB R2017b to explore plausible

541 underlying biophysical mechanisms. A 4-dimensional ordinary differential equation

542 model of a patch of neural membrane following the Hodgkin-Huxley formalism of

543 passive $\left(g_{\mathrm{L}}=0.033 \mathrm{mS} / \mathrm{cm}^{2}, \mathrm{E}_{\mathrm{L}}=-60 \mathrm{mV}, \mathrm{I}_{\mathrm{L}}=\mathrm{g}_{\mathrm{L}}\left(\mathrm{V}-\mathrm{E}_{\mathrm{L}}\right)\right)$ and voltage-dependent spiking $\mathrm{Na}+$

$544\left(\mathrm{gNa}_{\mathrm{Na}}=60.0 \mathrm{mS} / \mathrm{cm}^{2}, \mathrm{E}_{\mathrm{Na}}=+58 \mathrm{mV}, \mathrm{INa}_{\mathrm{Na}}=\mathrm{gNam}^{3} \mathrm{~h}\left(\mathrm{~V}-\mathrm{E}_{\mathrm{Na}}\right)\right)$ and $\mathrm{K}+\left(\mathrm{gK}_{\mathrm{K}}=5 \mathrm{mS} / \mathrm{cm}^{2}, \mathrm{E}_{\mathrm{K}}=-85\right.$

$\left.545 \mathrm{mV}, \mathrm{I}_{\mathrm{K}}=\mathrm{gkn}^{4}\left(\mathrm{~V}-\mathrm{E}_{\mathrm{K}}\right)\right)$ conductances was solved using Euler integration with a timestep of 
$546 \quad 0.005$ msec. First order kinetics of gating variables $m, h$, and $n$ were modeled as in

547 previously established models of this form ${ }^{57}$. Slowly changing net synaptic input and

548 extracellular ion gradient changes were considered to constitute a net external drive

549 modeled as an injected inward current. This current follows a temporal form

550 hypothesized to drive human neocortical neurons during secondarily generalized

551 seizures based on the dynamic membrane potential decoding analysis performed here.

552 Fast synaptic inputs were modeled as conductances with a maximum conductance

$553 \mathrm{~g}_{\mathrm{syn}}=0.15 \mathrm{mS} / \mathrm{cm}^{2}$ and an exponential decay time course of 5 milliseconds gated by

554 input spike times generated by a Poisson process with a linearly increasing rate

555 parameter from 0.001 to $0.2 \mathrm{~Hz}$ representing increasing input firing rates across seizure.

556 Analysis of the resulting spike trains was completed in the same manner as dynamic

557 membrane potential trajectory decoding was performed for the observed extracellular

558 data.

\section{Statistical analyses}

561 In performing hypothesis testing on various metrics describing activity amongst FS and

562 RS units including peak firing rate difference, mean cessation time difference, and mean

563 correlation between spike firing rate and action potential amplitude at time of cessation,

564 we employed bootstrap-based methods to quantify the uncertainty in these metrics. For

565 peak firing rate and cessation time differences this involved combining all relevant unit

566 measurements into a single population, randomly reshuffling RS and FS labels amongst

567 this population, and recomputing the relevant difference metrics $N_{\text {bootstrap }}$ times as

568 indicated to generate a distribution of the metric for random unit classifications. The 
569 probability of a Type-I (false positive) error, the p-value, was then reported as the area

570 under the distribution corresponding to values more extreme than the observed value

571 for the original data. For testing the positivity of the mean correlation between spike

572 firing rate and action potential amplitude at time of cessation, this involved first removing

573 correlation coefficients in the time series corresponding to a linear regressions involving

574 spike rates of less than $5 \mathrm{~Hz}$. Then the coefficients at each unit's detected cessation

575 time were resampled with replacement in 20 unit subpopulations 50,000 times (unless

576 otherwise specified) and averaged to generate a bootstrapped sample mean distribution

577 characterizing the variability in this mean relative to zero. The probability of a Type-I

578 (false positive) error that the observed mean coefficient was greater than zero by

579 chance, the p-value, was then reported as the area under the distribution corresponding

580 to values equal to or less than zero. To nonparametrically test the significance of

581 differences in paired measures at cessation and pause times within single units, we

582 employed the right-sided Wilcoxon signed rank test (RMatlab2017b).

584 Extended Data / Supplementary Information

5859 Extended Data Figures (+ legends) are included. 
medRxiv preprint doi: https://doi.org/10.1101/2020.10.09.20204206; this version posted October 20, 2020. The copyright holder for this preprint

(which was not certified by peer review) is the author/funder, who has granted medRxiv a license to display the preprint in perpetuity. It is made available under a CC-BY-NC-ND 4.0 International license.

\section{ACKNOWLEDGEMENTS}

599 We would like to thank the patient volunteers. This work was supported by the American

600 Epilepsy Society Junior Investigator Research Award, CURE Epilepsy Taking Flight

601 Award, NINDS F32-NS083208 and University of Michigan Startup Funds (OJA), NIH

602 R01-NS062092 (SSC) and NSF graduate student fellowships (TTJ \& EKWB).

603 
medRxiv preprint doi: https://doi.org/10.1101/2020.10.09.20204206; this version posted October 20, 2020. The copyright holder for this preprint (which was not certified by peer review) is the author/funder, who has granted medRxiv a license to display the preprint in perpetuity.

It is made available under a CC-BY-NC-ND 4.0 International license.

\section{FIGURES AND FIGURE LEGENDS}


medRxiv preprint doi: https://doi.org/10.1101/2020.10.09.20204206; this version posted October 20, 2020. The copyright holder for this preprint (which was not certified by peer review) is the author/funder, who has granted medRxiv a license to display the preprint in perpetuity.

It is made available under a CC-BY-NC-ND 4.0 International license .
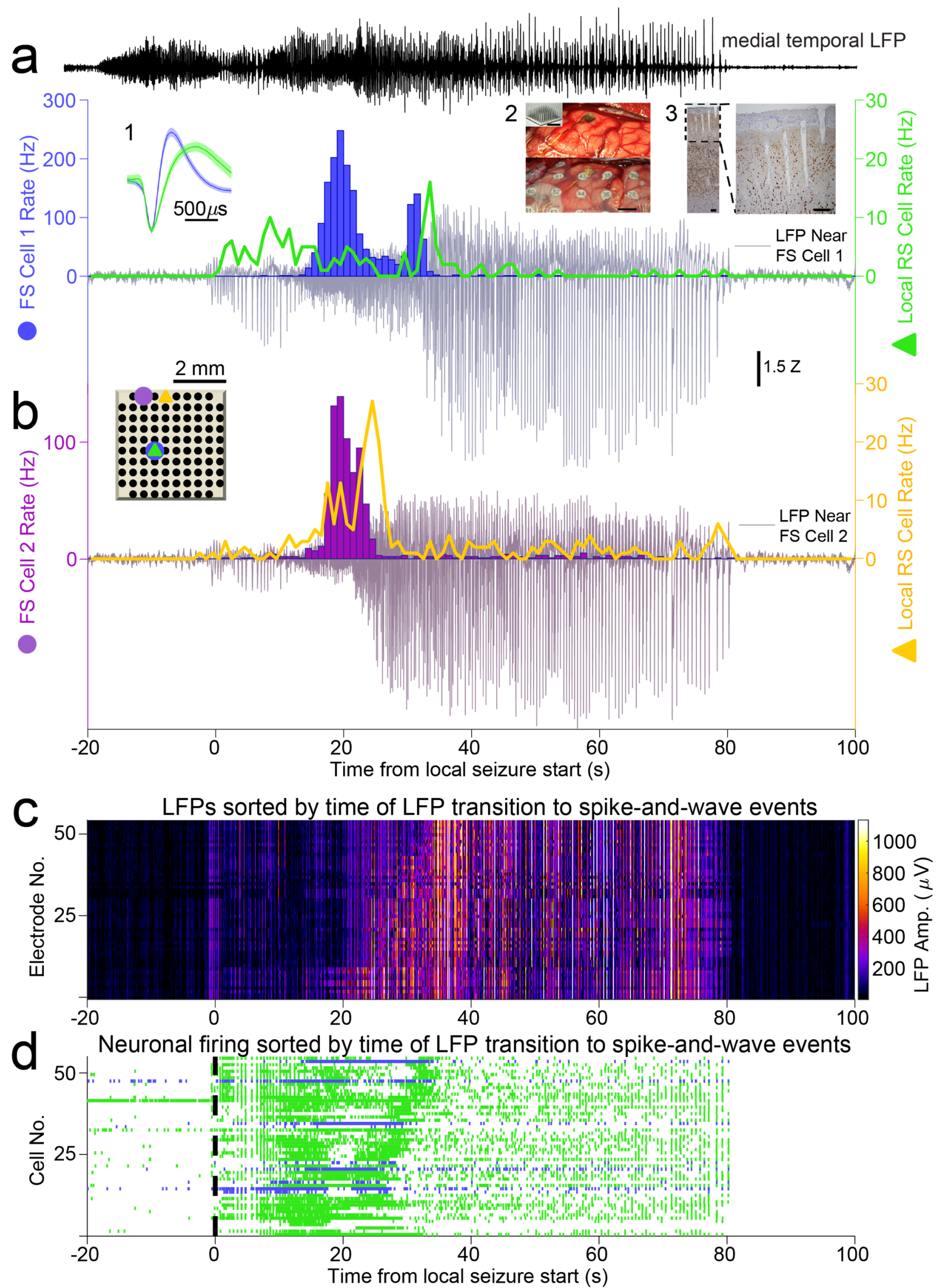
medRxiv preprint doi: https://doi.org/10.1101/2020.10.09.20204206; this version posted October $20,2020$. The copyright holder for this preprint (which was not certified by peer review) is the author/funder, who has granted medRxiv a license to display the preprint in perpetuity.

606

607

608

609

610

611

612

613

614

615

616

617

618

619

620

621

622

623

624

625

626

627

628

629

630

631

632

633

634

635

636

637

638

639

640

641

642

643

644

645

646

647

648

649

650 Figure 1: Human neocortical inhibitory and excitatory neurons have different temporal profiles
relative to secondarily generalized focal seizure progression on local electrodes

a. Upper. Electrocorticogram trace (ECoG, black) from contact closest to source of focal seizure in hippocampus of Patient $A$. Note its time of initiation at $T=-20$ seconds, substantially preceding the start of the seizure in neocortex. Lower. The firing rate of a single FS cell (blue), the firing rate of a single RS cell recorded from the same electrode (green) and the local field potential (LFP, gray, recorded from the same electrode as the FS cell) during a seizure recorded from Patient A. Note the decrease in LFP amplitude as the FS cell starts firing, followed by a dramatic increase in LFP seizure amplitude after the FS cell decreases its rate at $T=35$ seconds. RS cell quickly increases its firing rate as the seizure first spreads to the NeuroPort array ( $T=0$ seconds), then decreases in rate slightly as the FS cell switches on, and finally settles into a lower firing rate regime during the large spike-and-wave events that dominates the remainder of the seizure after FS cell cessation. Inset shows the mean normalized extracellular action potential waveforms (with $99 \%$ confidence intervals in lighter shading) of FS Cell 1 (blue) and the neighboring RS cell (green). Inset 1: the mean normalized extracellular action potential waveforms (with $99 \%$ confidence intervals in lighter shading) of FS Cell 1 (blue) and the neighboring RS cell (green). Inset 2: The implanted microelectrode array (Top) with overlaid clinical grid electrodes (Bottom); Scale bar: $1 \mathrm{~cm}$. Top left corner shows the array before implantation. Scale bar: $200 \mu \mathrm{m}$. Inset 3: Histology of resected tissue showing the NeuN-stained neurons in the full neocortical column and electrode tracts and an enlarged image (Right) showing that the array targeted layer 3 of the neocortex. Scale bars: $400 \mu \mathrm{m}$.

b. The inset shows a schematic of the array and the location of two simultaneously recorded FS cells separated by $\sim 2 \mathrm{~mm}$ : FS Cell 1 (blue, firing rate shown in Fig. 1c) and FS Cell 2 (purple). FS Cell 2 approached cessation at $T=24$ seconds, well before FS Cell 1. The LFP (grayish-purple) recorded at the same location as FS Cell 2 dramatically increases at the same time as FS Cell 2 decreases firing, well before the increase seen in the LFP recorded next to FS Cell 1. These suggest the activity of FS cells during human seizures is strongly correlated to the local intensity of seizure waves. FS Cell 2 activity cessation again precedes a sharp increase in local RS cell activity (gold), further suggesting an important role of FS cells in controlling local activity during seizure progression.

c. Heatmap shows local LFP amplitude (absolute value) over time on each electrode in NeuroPort array exhibiting classifiable units as each row, sorted by time of start of spike-and-wave event and with brighter colors indicating larger amplitudes. Note the increasing delay to start of spikeand-wave event suggesting different dynamics to seizure spread across the array over the timecourse of approximately 20 seconds.

d. Raster plot showing spike times of all cells on NeuroPort array in Patient $A$ that could be classified into FS (blue) or RS (green) categories with rows sorted by the same order as in (C). Note the increasing delay to reduction in spike density corresponding to LFP transition to spikeand-wave events suggesting control of local seizure progression by local cellular spiking activity. 

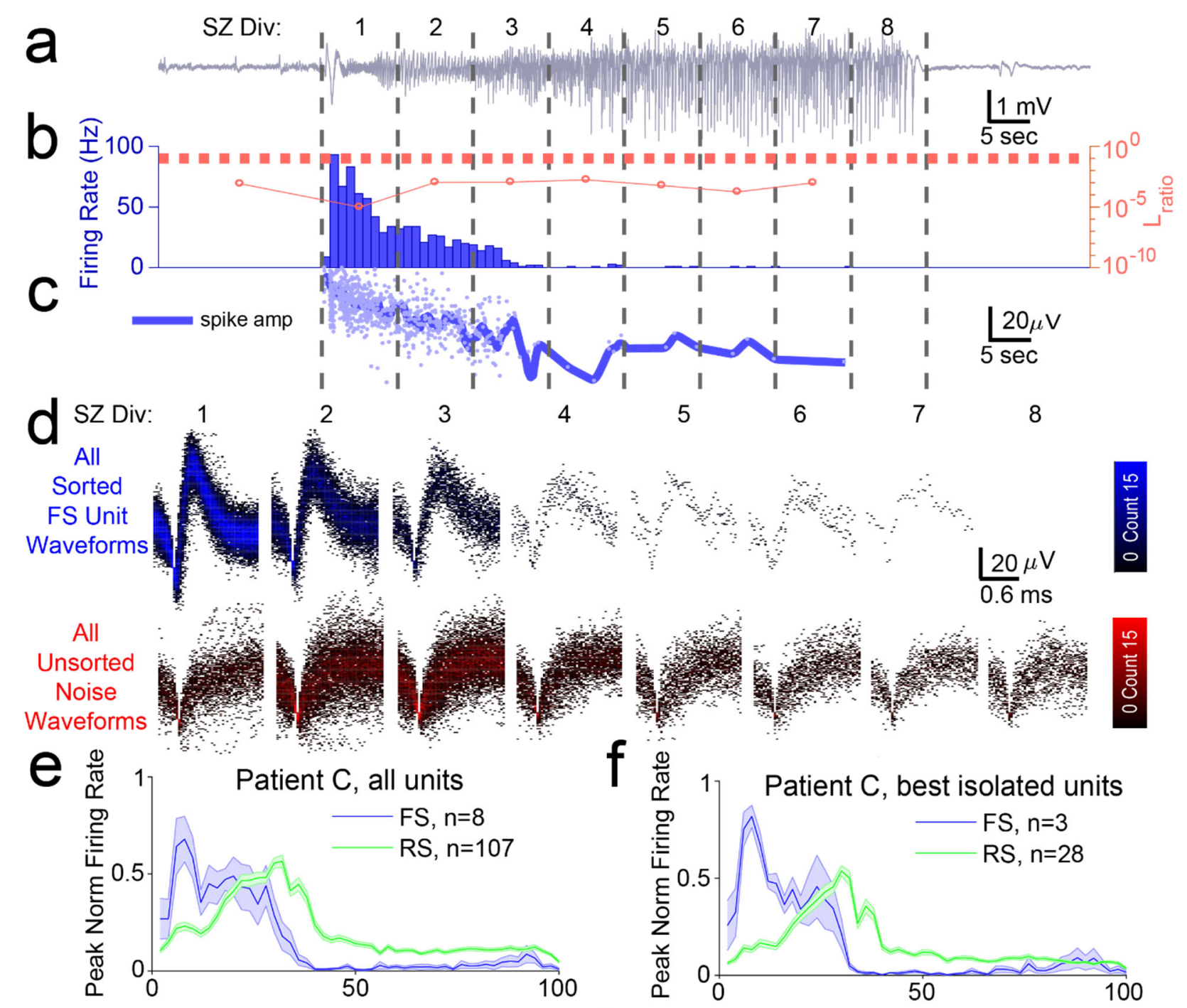
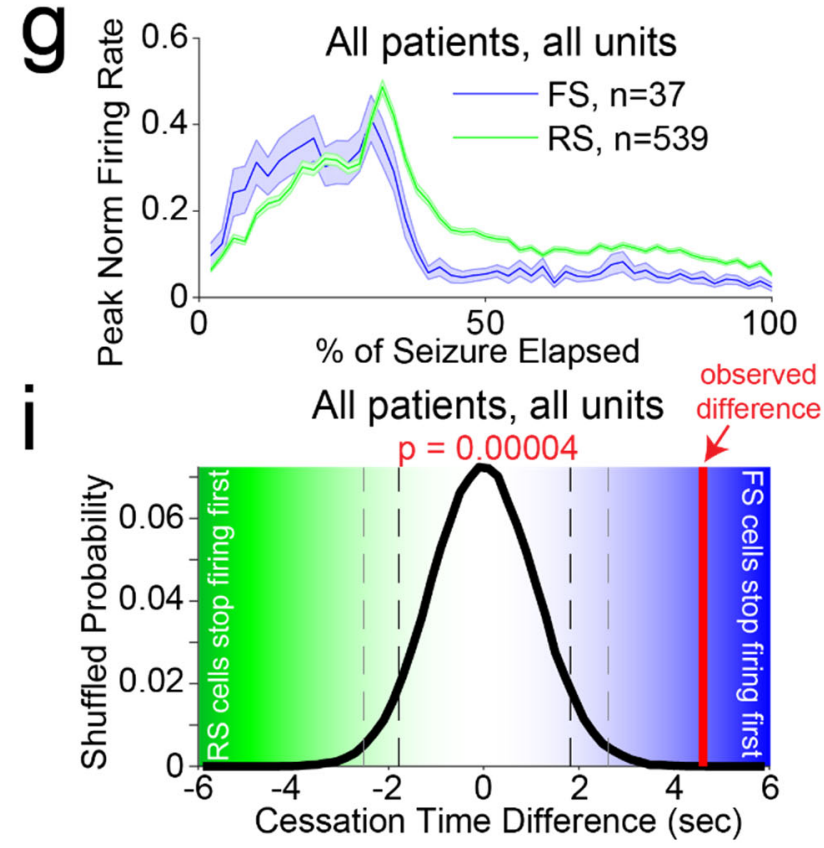

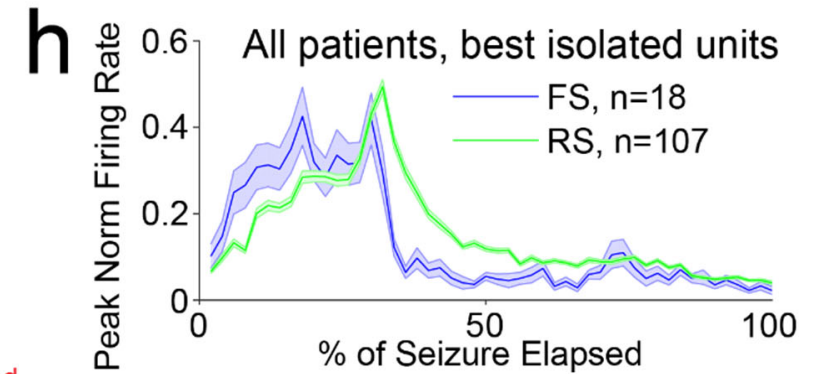

All patients, best isolated units

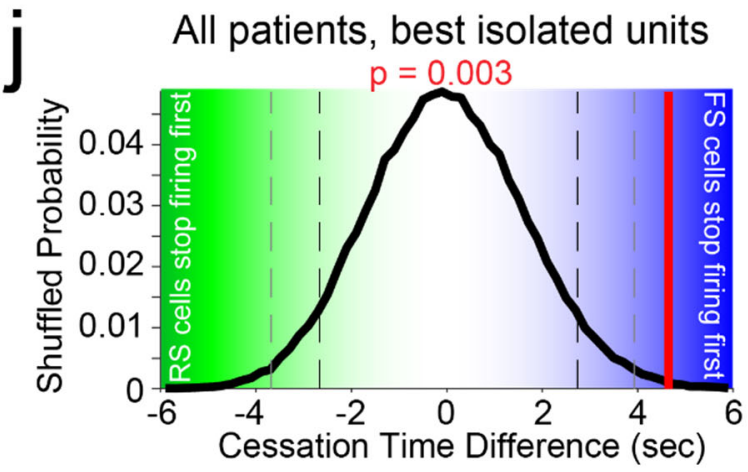


medRxiv preprint doi: https://doi.org/10.1101/2020.10.09.20204206; this version posted October $20,2020$. The copyright holder for this preprint (which was not certified by peer review) is the author/funder, who has granted medRxiv a license to display the preprint in perpetuity.

It is made available under a CC-BY-NC-ND 4.0 International license .

652

653

654

655

656

657

658

659

660

661

662

663

664

665

666

667

668

669

670

671

672

673

674

675

676

677

678

679

680

681

682

683

684

685

686

687

688

689

690

691

692

693

694

695

696

697

698

699

700

701

702

703

704

705

706

707

Figure 2: Analyzing unit subpopulations by isolation quality demonstrates consistent cell-type specific activity profiles and cessation order despite changing unit amplitude and noise structure.

a. LFP in Patient $\mathrm{C}$ indicating seizure as split into 8 equal time divisions for analysis of unit isolation quality across duration of seizure.

b. Bar graph shows firing rate in 1 second bins of best-isolated example FS unit (blue) in Patient $\mathrm{C}$. Dotted red line indicates threshold used to determine best-isolated units using the dynamic $L_{\text {ratio }}$ measure (see Methods) in each time division of seizure. Line plot indicates dynamic Lratio $_{\text {in each }}$ division (red) and shows large separation of example FS unit from noise in feature space used for clustering throughout the seizure (note log scale).

c. Line plot showing average spike amplitude (dark blue) and individual spike amplitudes (light blue) of example FS unit over course of seizure in Patient C. Note that even as amplitude decreases the unit remains well-isolated from noise as quantified by dynamic Lratio across seizure.

d. Time-voltage histogram of all threshold crossings assigned to this example FS unit (blue, Upper) and to noise (red, Lower) in eight divisions of seizure in Patient C. Shows unit waveforms are visually distinguishable from threshold crossings assigned as noise across seizure.

e. Average firing rate traces across seizures for each cell type group in Patient $C$, with $y$-axis normalized to firing rate peak and $\mathrm{x}$-axis normalized to total seizure duration before averaging. Note right-shifted rate profile of RS units over course of seizure as compared to FS units.

f. Average firing rate traces across seizures for each cell type group using only best-isolated units (see Methods) in Patient $\mathrm{C}$, with $\mathrm{y}$-axis normalized to firing rate peak and $\mathrm{x}$-axis normalized to total seizure duration before averaging. Note right-shifted rate profile of best-isolated RS units over course of seizure as compared to best-isolated FS units.

g. Average firing rate traces across seizures for each cell type group across all patients, with y-axis normalized to firing rate peak and $\mathrm{x}$-axis normalized to total seizure duration before averaging. Note right-shifted rate profile of RS units over course of seizure as compared to FS units.

h. Average firing rate traces across seizures for each cell type group using only best-isolated units (see Methods) across all patients, with y-axis normalized to firing rate peak and x-axis normalized to total seizure duration before averaging. Note right-shifted rate profile of best-isolated RSclassified units over course of seizure as compared to best-isolated FS-classified units.

i. Observed time difference (solid red line) between mean RS activity cessation timing $(n=399)$ and mean FS activity cessation timing $(n=37)$ in relation to probability distribution of this timing difference across random label reshufflings of unit cell type labels $\left(N_{\text {shuffles }}=100,000\right.$; solid black line). P-value indicates probability of observing a value equal to or more extreme than the observed value simply by random assignment of cell type to each unit. Values on the right half correspond to a positive difference between RS and FS cessation, with larger values associated with increasing certainty that FS cells stop firing before RS cells. Values on the left half correspond to a negative difference between RS and FS cessation times, with larger values associated with increasing certainty that RS cells stop firing before FS cells.

j. Observed time difference (solid red line) between mean best-isolated RS activity cessation timing $(\mathrm{n}=83$; Lratio $<0.1$ during middle 3 seizure divisions) and mean best-isolated FS activity cessation timing ( $n=17$; Lratio $<0.1$ during middle 3 seizure divisions) in relation to probability distribution of this timing difference across random label reshufflings of unit cell type labels ( $N_{\text {shuffles }}=100,000$; solid black line). P-value indicates probability of observing a value equal to or more extreme than the observed value simply by random assignment of cell type to each unit. Values on the right half correspond to a positive difference between best-isolated RS and bestisolated FS cessation times, with larger values associated with increasing certainty that best- 
medRxiv preprint doi: https://doi.org/10.1101/2020.10.09.20204206; this version posted October 20, 2020. The copyright holder for this preprint (which was not certified by peer review) is the author/funder, who has granted medRxiv a license to display the preprint in perpetuity. It is made available under a CC-BY-NC-ND 4.0 International license. negative difference between best-isolated RS and best-isolated FS cessation, with larger values cells. 

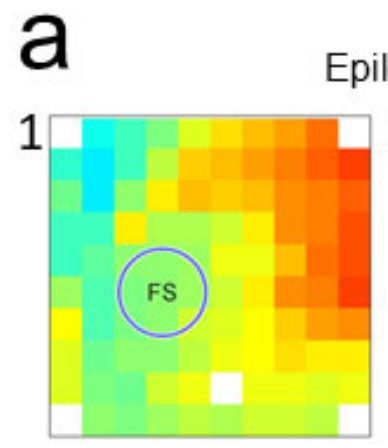

Epileptic traveling wave while FS cell is still firing

\section{5}

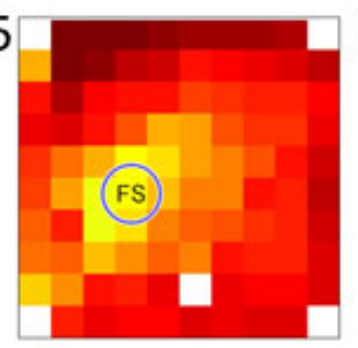

$O=2$ spikes in $10 \mathrm{~ms}$ window
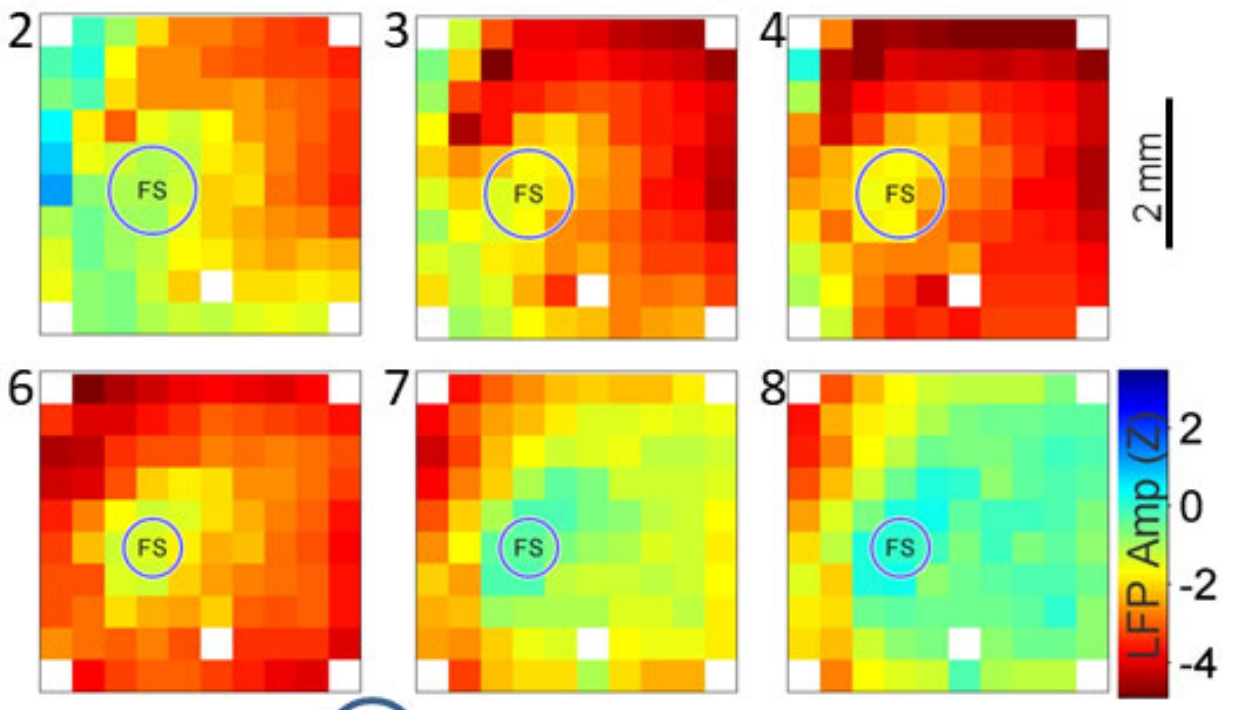

$=3$ spikes in $10 \mathrm{~ms}$ window b

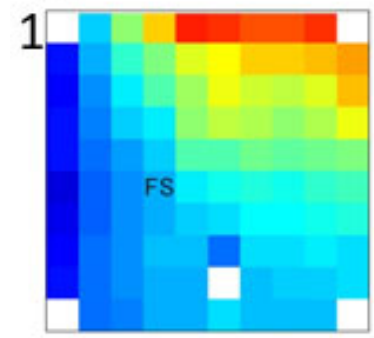

\section{5}

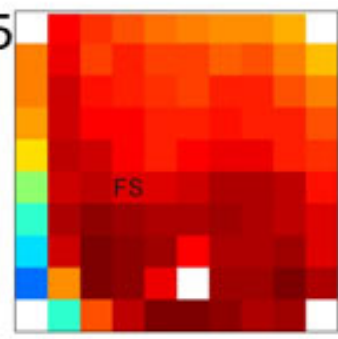

Epileptic traveling wave after FS cell has stopped firing
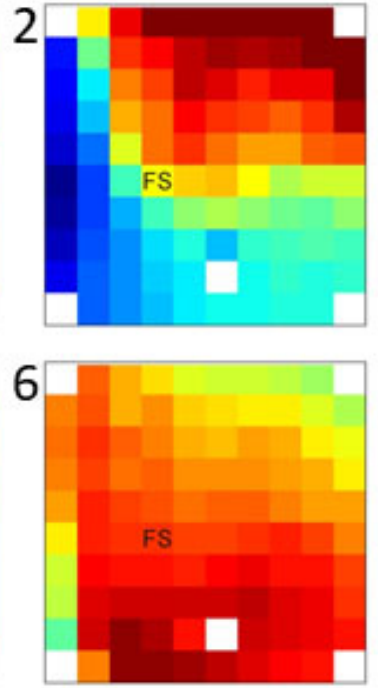
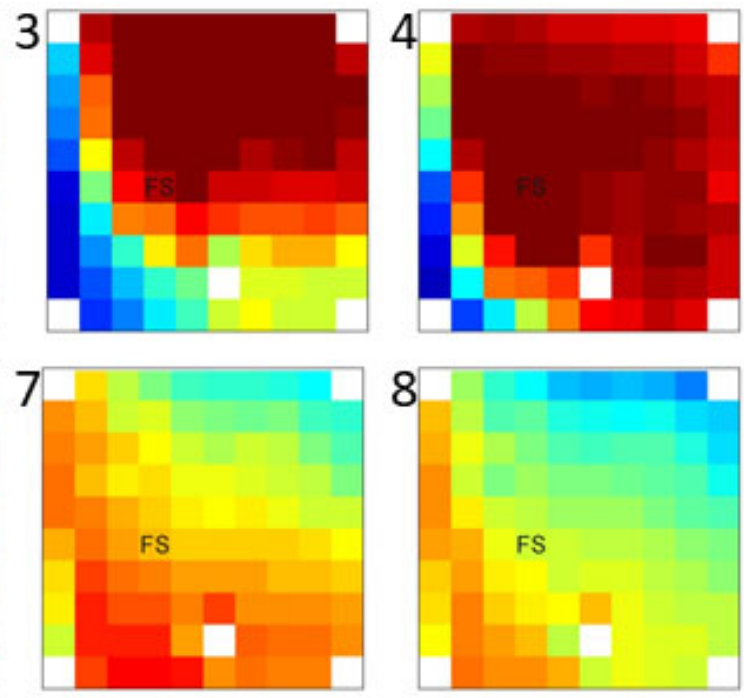

Figure 3: Fast-spiking inhibitory neurons, when still firing, impede the spread of epileptic traveling waves. 
medRxiv preprint doi: https://doi.org/10.1101/2020.10.09.20204206; this version posted October 20, 2020. The copyright holder for this preprint

(which was not certified by peer review) is the author/funder, who has granted medRxiv a license to display the preprint in perpetuity.

It is made available under a CC-BY-NC-ND 4.0 International license .

a. An example of a traveling wave recorded 30 seconds after the start of a seizure in Patient $A$. The FS cell located at the position marked "FS" was firing at high rates at this time. The 8 snapshots $(1-8)$ are taken over a 35 ms interval as the traveling LFP wave starts in the top-right corner of the array and travels across the array. The traveling wave does not fully invade the region of neocortex containing the active FS cell, resulting in lower amplitude LFPs around the FS cell. In each subfigure, each square denotes a single LFP sensor, and white squares indicate omitted sensors.

731

732

b. An example of a traveling wave recorded 49 seconds after the start of the same seizure. In the absence of FS cell firing, the epileptic traveling wave moves unimpeded through the array, fully invading the region around the marked FS cell and resulting in larger amplitude LFPs at all locations. 


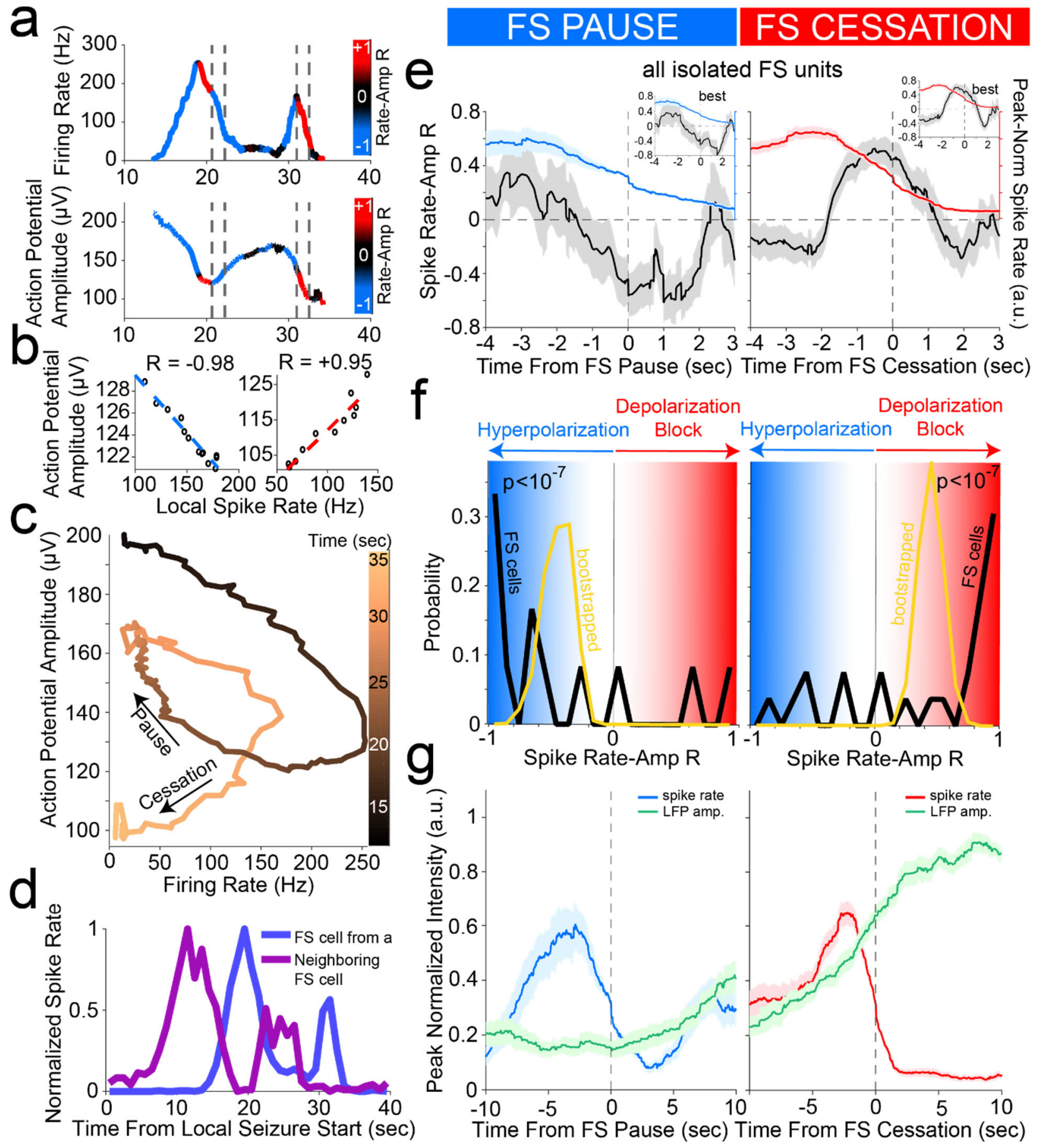

Figure 4. Cessation of individual FS unit activity is consistently associated with inferred membrane potential signatures of depolarization block, despite prior hyperpolarized pauses

a. Firing rate (upper) and trough-to-peak spike amplitude (lower) of example FS unit in Patient A, color-coded by the local correlation between spike rate and amplitude (in 1 second time bins) as an extracellular proxy for membrane potential trajectory and subthreshold input history. Dotted lines indicate starts and ends of two time periods of firing rate suppression characterized by different membrane potential signatures further characterized in (B), namely a negative correlation regime corresponding to inhibition followed by a positive correlation regime 
medRxiv preprint doi: https://doi.org/10.1101/2020.10.09.20204206; this version posted October $20,2020$. The copyright holder for this preprint (which was not certified by peer review) is the author/funder, who has granted medRxiv a license to display the preprint in perpetuity.

It is made available under a CC-BY-NC-ND 4.0 International license .

corresponding to over-excitation ending in firing rate cessation putatively though depolarization block.

b. Example of negative correlation (left) between local spike rate and amplitude in first time period indicated by dotted lines in $(\mathrm{A})$ and example of positive correlation (right) between local spike rate and amplitude in second time period indicated by dotted lines in (A). Least squares linear fit indicated in dotted lines following color scheme in $(A)$ with Pearson's correlation coefficient indicated above each plot.

c. Trajectory of unit activity over time during seizure in local spike rate vs spike amplitude space, with increasing time indicated by increasingly lighter copper color. The first time period of firing rate reduction in dotted lines in $(A)$ is indicated with an arrow as "Pause" and the second time period of firing rate reduction in dotted lines in $(A)$ is indicated with an arrow as "Cessation."

d. Firing rate of unit from $(A)$ with neighboring FS unit firing rate overlaid, giving further evidence that first period of firing rate suppression corresponds to inhibition from local FS units while second period of firing rate suppression does not correspond to inhibition from local FS units.

e. Unit cessation-triggered population average of the time course of novel membrane potential regime measure, i.e. the correlation coefficient relating spiking amplitude and rate in a local time window, around the two significant descents in firing rate (below $30 \%$ of peak rate) that occur in sequence during seizure. These are designated as pause (left panel) and cessation (right panel). Left panel shows population average firing rate (blue) and inferred membrane potential regime (black) aligned according to the time of pause in each unit, for all FS units displaying a pause $(n=14)$, with inset showing average for best-isolated FS units displaying a pause $(n=10)$. Right panel shows population average firing rate (red) and inferred membrane potential regime (black) aligned according to the cessation time of each unit, for all FS units $(n=37)$, with inset showing average for best-isolated FS units $(n=24)$.

f. Probability distribution of membrane potential regime measure (spike rate-amplitude correlation; black line) at the time of pause (left panel) for FS unit pausing subpopulation ( $n=14)$ with sample mean distribution (gold line; resampling size $n=10, N_{\text {bootstrap }}=50,000$ ) showing the mean correlation to be significantly below zero, i.e. in the hyperpolarized membrane potential regime (blue). In combination with its declining firing rate, this is indicative of widespread inhibition across this subpopulation at the time of pause. The population distribution of inferred membrane potential regime is also shown at the time of cessation (right panel) for the full FS unit population $(n=37)$ with sample mean distribution (gold line; resampling size $\left.n=10, N_{\text {bootstrap }}=50,000\right)$ showing the mean correlation to be significantly above zero, i.e. in the highly depolarized membrane potential regime (red). This is indicative of widespread depolarization block occurring across FS population at the time of cessation.

g. Unit cessation-triggered population average of the time course of same-electrode LFP amplitude around unit activity pause (left panel) and cessation (right panel). In particular, left panel shows population average firing rate (blue) and LFP amplitude (black) aligned according to the time of pause in each unit, for all FS units displaying a pause $(n=14)$. Right panel shows population average firing rate (red) and LFP amplitude (black) aligned according to the time of cessation in each unit, for all FS units ( $n=37$ ), indicative of larger LFP increase associated with second FS firing rate descent (cessation) than with first (pause) despite comparable local firing rates in the two conditions. 


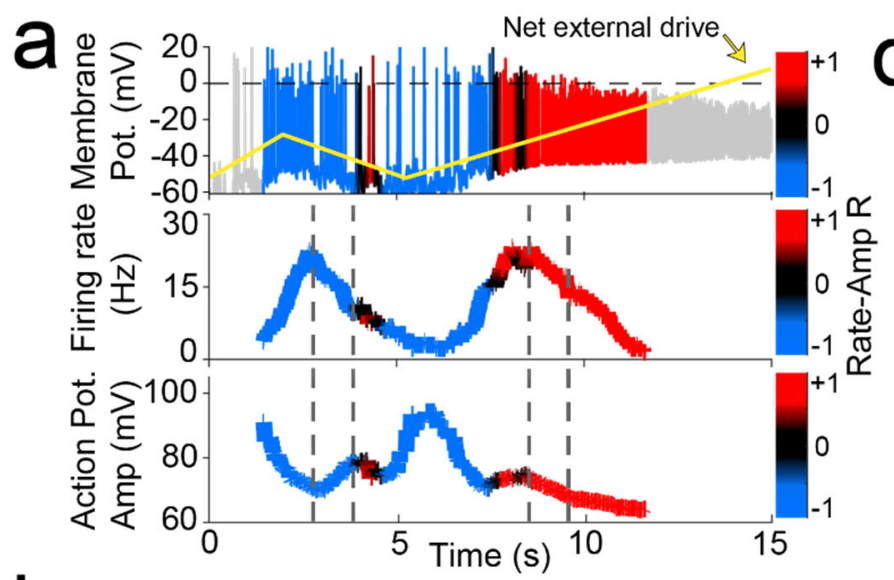

b
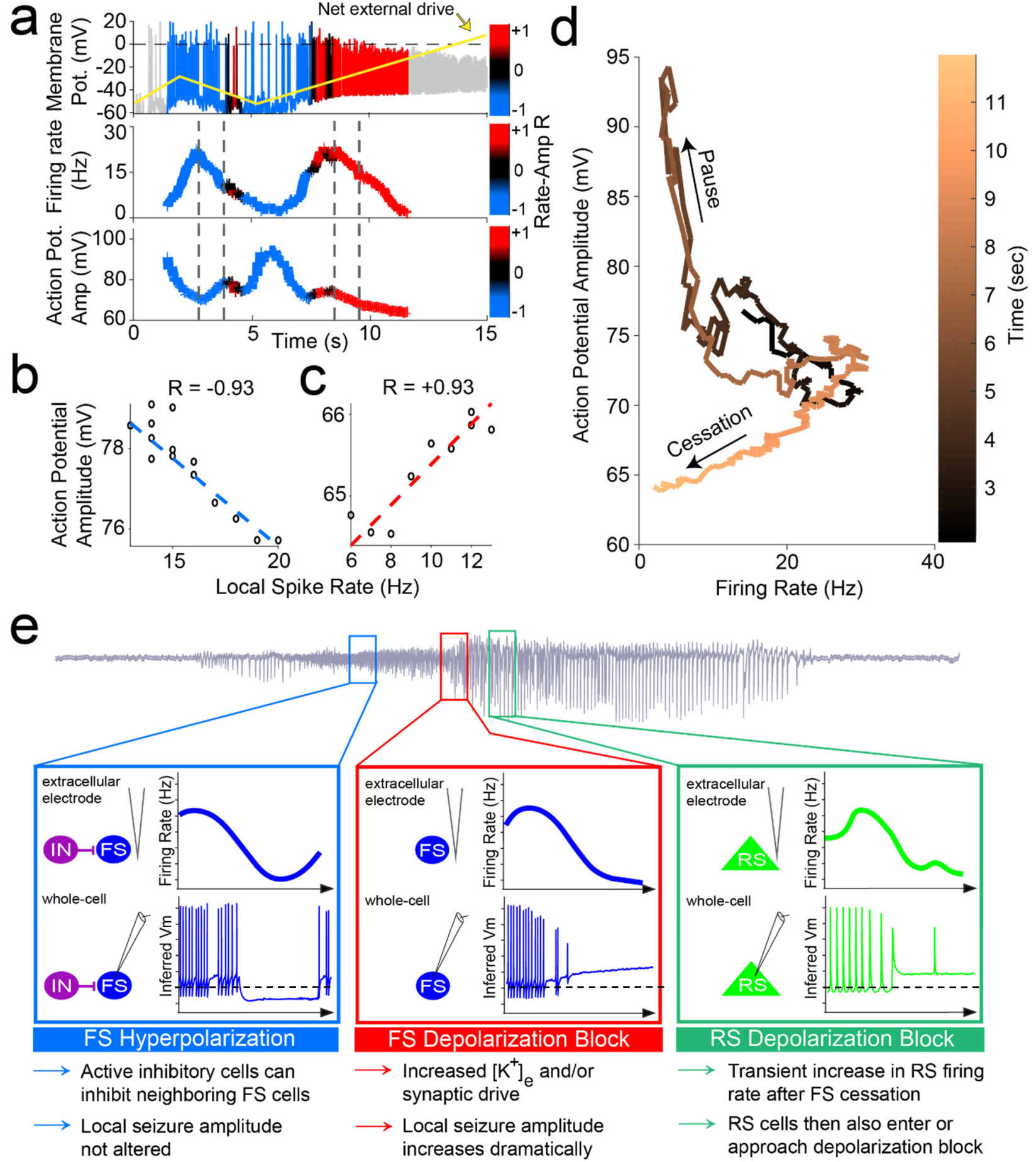

Figure 5. Mechanistic model of unit dynamics across seizure progression: inhibition followed by over-excitation in conductance-based neuron model reproduces key features of extracellular unit behavior during seizures.

a. Simulated membrane potential in conductance-based spiking model color-coded by the local correlation between spike rate and amplitude and with net excitatory input indicated by gold line (upper panel). Shows what is hypothesized to be happening within cortical cells during seizure progression as inferred from extracellular spike shape and rate dynamics. Firing rate (middle 
panel) and trough-to-peak spike amplitude (lower panel) of the same model, color-coded by the local correlation between spike rate and amplitude as an extracellular proxy for membrane potential and subthreshold input history. Dotted lines indicate starts and ends of two time periods of firing rate suppression characterized by different membrane potential signatures further characterized in (b) and (c).

b. Example of negative correlation between local spike rate and amplitude during firing pause in (a), corresponding to activity shutdown via inhibition. Least squares linear fit indicated in dotted lines following color scheme in (a) with Pearson's correlation coefficient indicated above plot.

c. Example of positive correlation between local spike rate and amplitude during firing cessation, corresponding to activity shutdown via over-excitation. Least squares linear fit indicated in dotted lines following color scheme in (a) with Pearson's correlation coefficient indicated above plot.

d. Trajectory of unit activity over time during seizure in local spike rate vs spike amplitude space, with increasing time indicated by increasingly lighter copper color. The first time period of firing rate reduction in (a) is indicated with an arrow as "Pause" and the second time period of firing rate reduction is indicated with an arrow as "Cessation."

\section{e. Summary of observed dynamics in cell-type specific firing rate and inferred membrane potential trajectories.}

Blue box: Following seizure onset, some FS cells can stop firing for brief periods (as observed on extracellular electrodes, upper panel). This pause in firing is coupled with signs of hyperpolarization in the inferred membrane potential (lower panel).

Red box: As the seizure starts to transition to a dramatically higher amplitude FS cells stop firing (as observed on extracellular electrodes, upper panel). This cessation is coupled with signs of excessive depolarization in the inferred membrane potential (lower panel; resting membrane potential indicated as dashed line). This is likely due to elevated extracellular potassium ion concentrations by this point of the seizure or increased synaptic drive.

Green box: The subsequent stage of high amplitude spike-and-wave rhythms corresponds to a transient increase and then decrease of firing rate amongst RS cells (as observed on extracellular electrodes, upper panel). This decrease in firing rate is coupled with signs of excessive depolarization in the inferred membrane potential (lower panel). 


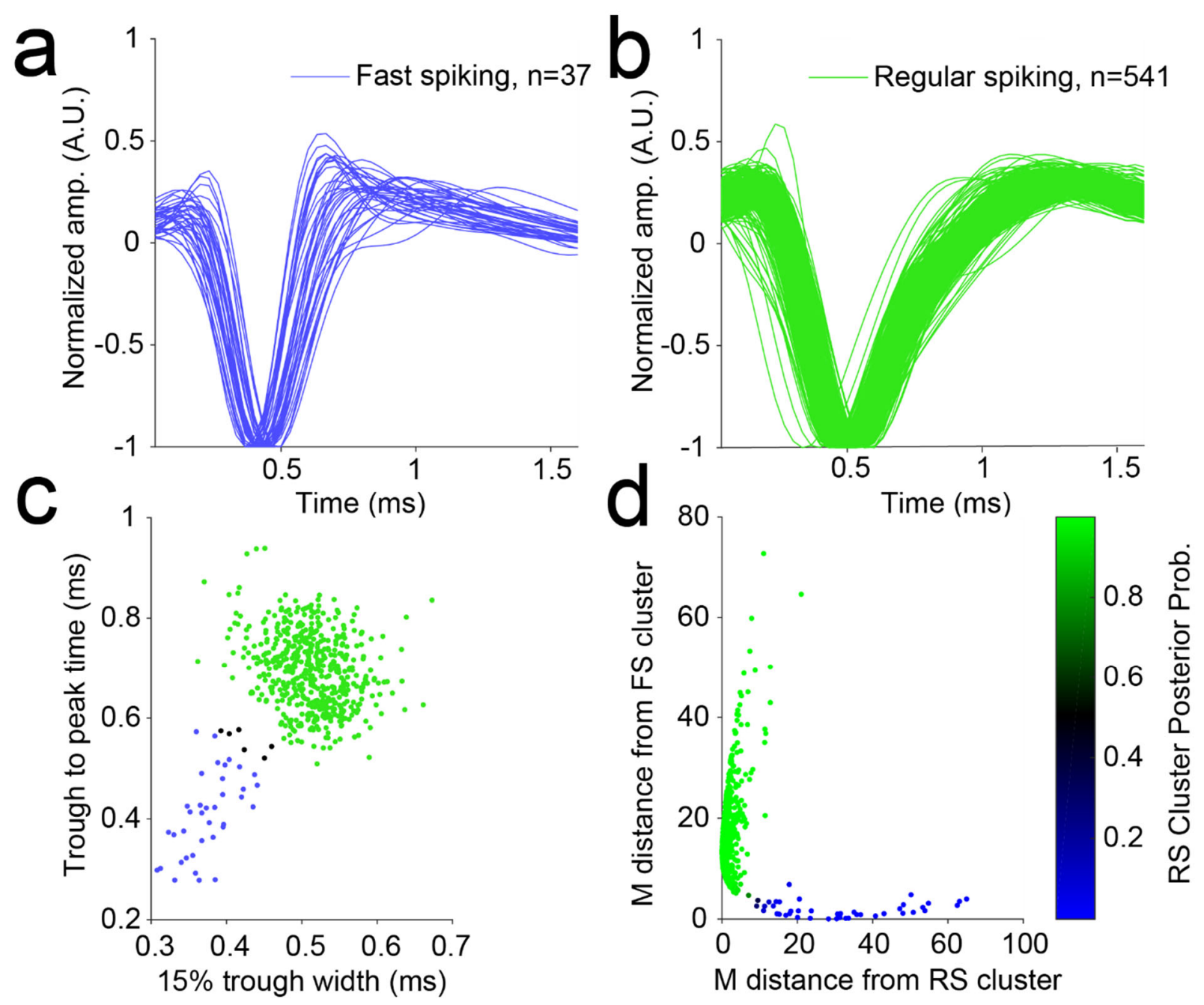

\section{Extended Data Figure 1: Human neural activity classification}

a. Average waveform of each FS-classified unit, normalized by the value the waveform reaches at its trough. The overlaid average waveforms show visual consistency amongst all units classified as FS and as having spike widths narrower than those of RS-classified units.

b. Average waveform of each RS-classified unit, normalized by the value the waveform reaches at its trough. The overlaid average waveforms show visual consistency amongst all units classified as RS and as having spike widths wider than those of FS-classified units.

c. All units indicated as points in the average waveform feature space that produced optimal cluster separation, namely the width of the waveform at the potential corresponding to $15 \%$ of the potential at its trough and the time between the trough and peak of the waveform. Clustering was automated using a Gaussian Mixture Model where points with posterior probability exceeding 0.95 were assigned to the closest centroid. Black dots indicate units that did not exceed this threshold for either Gaussian cloud and were thus unclassified and not used in the remainder of the study.

d. Mahalanobis distance of each unit from both the RS and FS clusters with color indicating its posterior probability of belonging to the RS cluster. Closeness of points to both axes shows that 
medRxiv preprint doi: https://doi.org/10.1101/2020.10.09.20204206; this version posted October 20, 2020. The copyright holder for this preprint (which was not certified by peer review) is the author/funder, who has granted medRxiv a license to display the preprint in perpetuity.

864

865

the clusters are well-separated when accounting for their different variances along different

866 directions in feature space. 
medRxiv preprint doi: https://doi.org/10.1101/2020.10.09.20204206; this version posted October 20, 2020. The copyright holder for this preprint (which was not certified by peer review) is the author/funder, who has granted medRxiv a license to display the preprint in perpetuity.

It is made available under a CC-BY-NC-ND 4.0 International license .
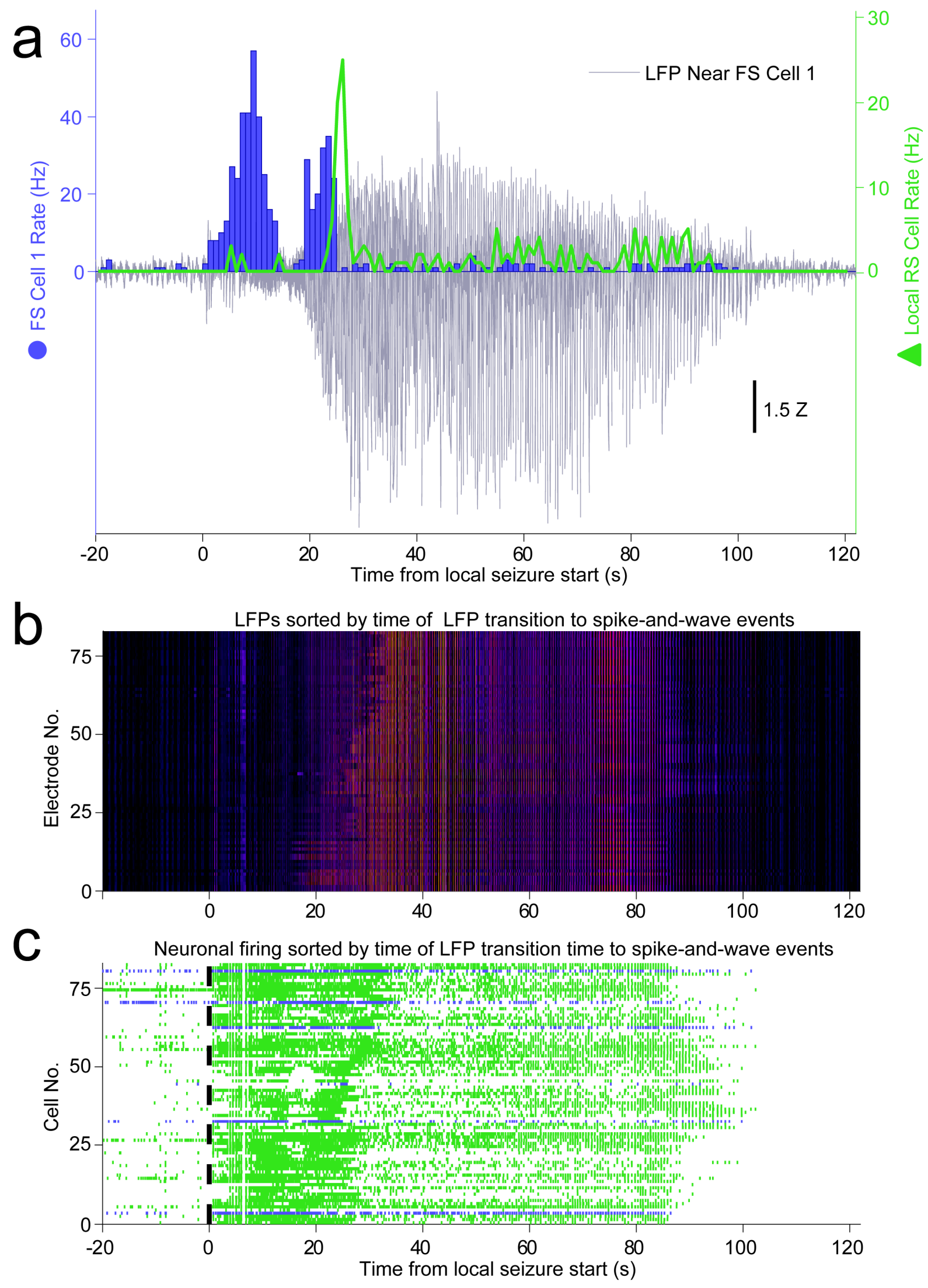
medRxiv preprint doi: https://doi.org/10.1101/2020.10.09.20204206; this version posted October 20, 2020. The copyright holder for this preprint

(which was not certified by peer review) is the author/funder, who has granted medRxiv a license to display the preprint in perpetuity.

It is made available under a CC-BY-NC-ND 4.0 International license.

868 Extended Data Figure 2: Human neocortical inhibitory and excitatory neuron activities have distinct temporal profiles relative to secondarily generalized focal seizure progression on local electrodes, Patient A, Seizure 2

a. The LFP (gray) recorded at the same location as FS Cell 1 (blue) dramatically increases at the same time as FS Cell 1 decreases firing. FS Cell 1 activity cessation again precedes a sharp increase in local RS cell activity (green), further suggesting an important role of FS cells in controlling local activity during seizure progression.

873

875

876

b. Heatmap shows local LFP amplitude (absolute value) over time on each electrode in NeuroPort array exhibiting classifiable units as each row, sorted by time of start of spike-and-wave event and with brighter colors indicating larger amplitudes.

c. Raster plot showing spike times of all cells on NeuroPort array in Patient B that could be classified into FS (blue) or RS (green) categories with rows sorted by the same order as in (B). Note the increasing delay to reduction in spike density corresponding to LFP transition to spikeand-wave events suggesting control of local seizure progression by local cellular spiking activity. 
medRxiv preprint doi: https://doi.org/10.1101/2020.10.09.20204206; this version posted October 20, 2020. The copyright holder for this preprint (which was not certified by peer review) is the author/funder, who has granted medRxiv a license to display the preprint in perpetuity.

It is made available under a CC-BY-NC-ND 4.0 International license .
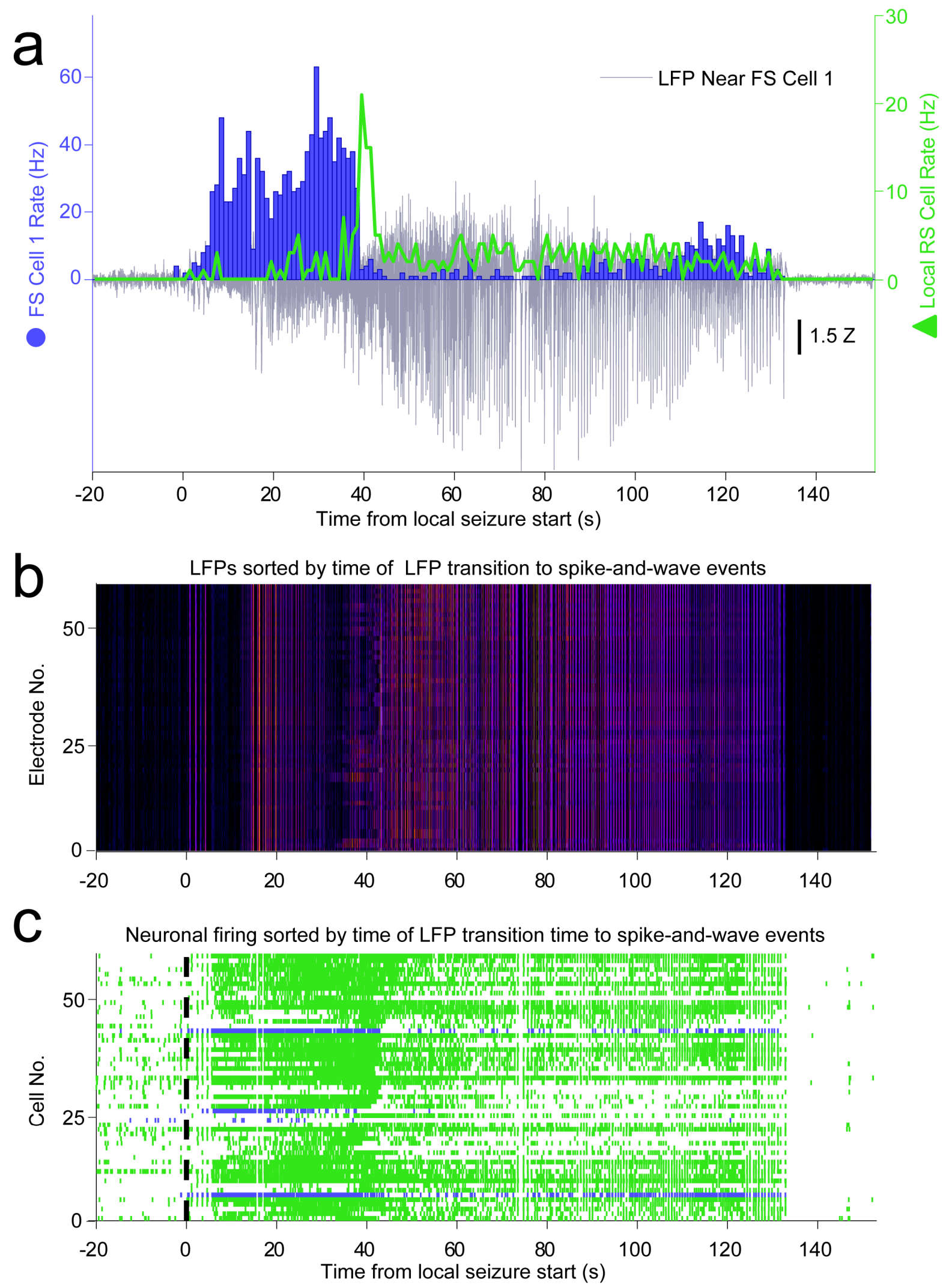
medRxiv preprint doi: https://doi.org/10.1101/2020.10.09.20204206; this version posted October 20, 2020. The copyright holder for this preprint

(which was not certified by peer review) is the author/funder, who has granted medRxiv a license to display the preprint in perpetuity.

It is made available under a CC-BY-NC-ND 4.0 International license.

883 Extended Data Figure 3: Human neocortical inhibitory and excitatory neuron activities have

884 distinct temporal profiles relative to secondarily generalized focal seizure progression on local electrodes, Patient C, Seizure 2

a. The LFP (gray) recorded at the same location as FS Cell 1 (blue) dramatically increases at the same time as FS Cell 1 decreases firing. FS Cell 1 activity cessation again precedes a sharp increase in local RS cell activity (green), further suggesting an important role of FS cells in controlling local activity during seizure progression.

889

890

891

892

893

894

895

896

897

b. Heatmap shows local LFP amplitude (absolute value) over time on each electrode in NeuroPort array exhibiting classifiable units as each row, sorted by time of start of spike-and-wave event and with brighter colors indicating larger amplitudes.

c. Raster plot showing spike times of all cells on NeuroPort array in Patient $\mathrm{C}$ that could be classified into FS (blue) or RS (green) categories with rows sorted by the same order as in (B). Note the increasing delay to reduction in spike density corresponding to LFP transition to spikeand-wave events suggesting control of local seizure progression by local cellular spiking activity. 
medRxiv preprint doi: https://doi.org/10.1101/2020.10.09.20204206; this version posted October 20, 2020. The copyright holder for this preprint (which was not certified by peer review) is the author/funder, who has granted medRxiv a license to display the preprint in perpetuity.

It is made available under a CC-BY-NC-ND 4.0 International license .
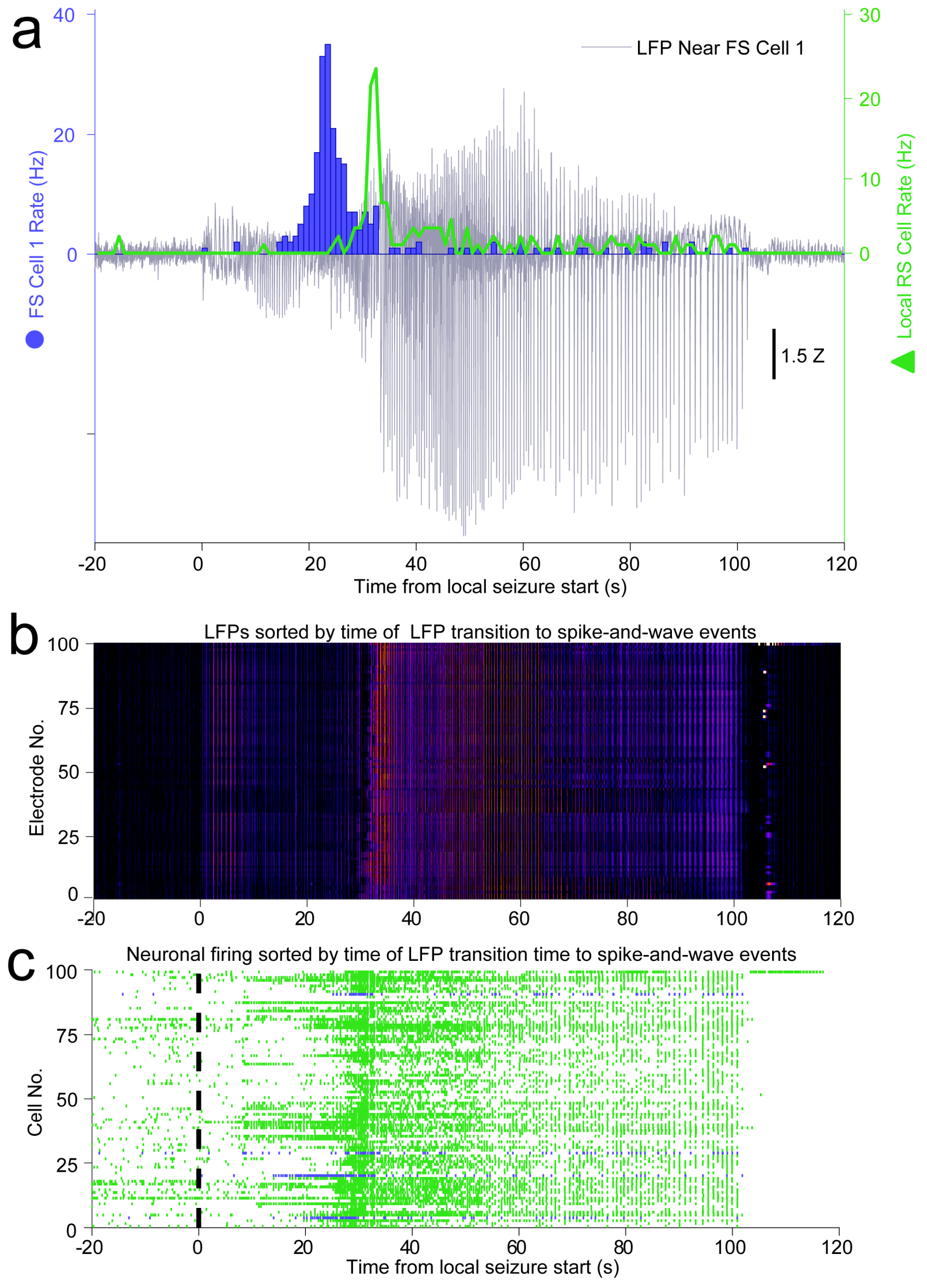
medRxiv preprint doi: https://doi.org/10.1101/2020.10.09.20204206; this version posted October 20, 2020. The copyright holder for this preprint

(which was not certified by peer review) is the author/funder, who has granted medRxiv a license to display the preprint in perpetuity.

It is made available under a CC-BY-NC-ND 4.0 International license.

899 Extended Data Figure 4: Human neocortical inhibitory and excitatory neuron activities have

900 distinct temporal profiles relative to secondarily generalized focal seizure progression on local 901 electrodes, Patient B, Seizure 1

902

903

904

905

906

907

908

a. The LFP (gray) recorded at the same location as FS Cell 1 (blue) dramatically increases at the same time as FS Cell 1 decreases firing. FS Cell 1 activity cessation again precedes a sharp increase in local RS cell activity (green), further suggesting an important role of FS cells in controlling local activity during seizure progression.

909

910

b. Heatmap shows local LFP amplitude (absolute value) over time on each electrode in NeuroPort array exhibiting classifiable units as each row, sorted by time of start of spike-and-wave event and with brighter colors indicating larger amplitudes.

911

c. Raster plot showing spike times of all cells on NeuroPort array in Patient $C$ that could be classified into FS (blue) or RS (green) categories with rows sorted by the same order as in (B). 
medRxiv preprint doi: https://doi.org/10.1101/2020.10.09.20204206; this version posted October 20, 2020. The copyright holder for this preprint (which was not certified by peer review) is the author/funder, who has granted medRxiv a license to display the preprint in perpetuity. It is made available under a CC-BY-NC-ND 4.0 International license .

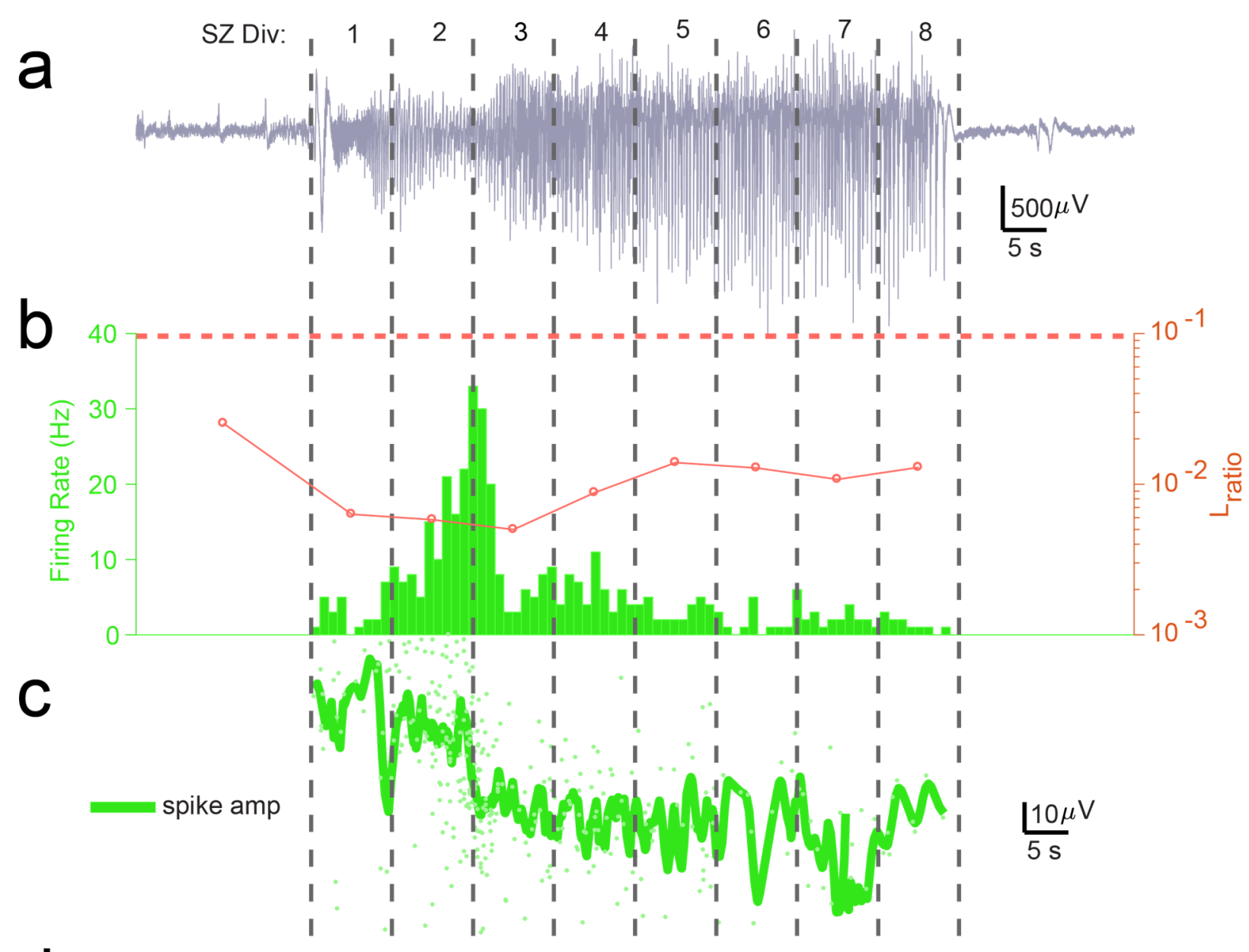

d

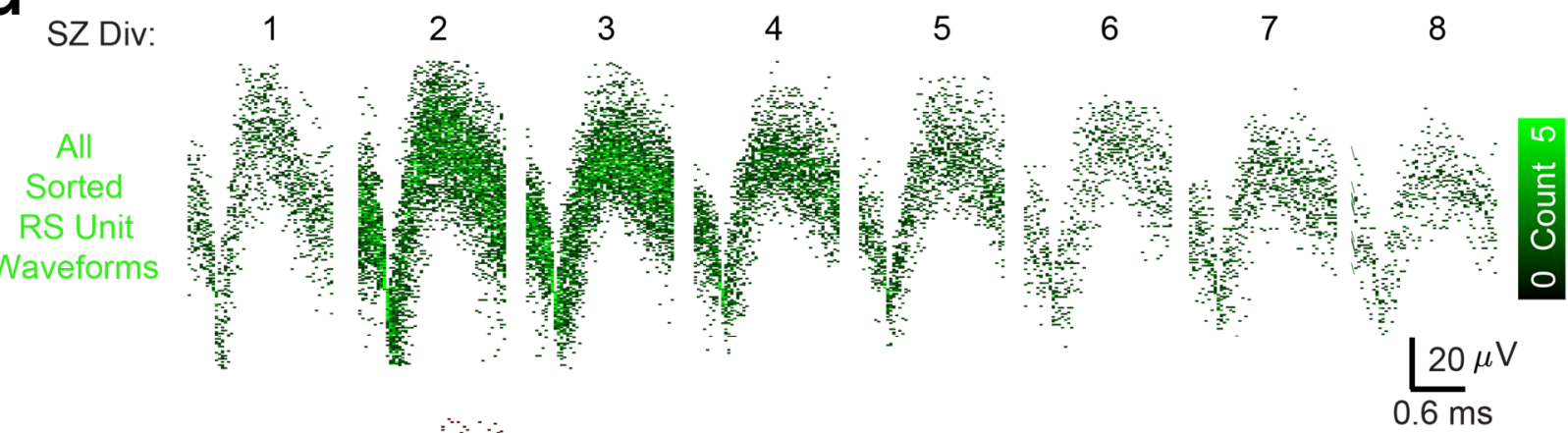

913 Extended Data Figure 5: Cluster isolation quality assessment suggests RS units are well-

914 isolatable across seizure despite changing unit amplitude and noise structure, allowing analysis 915 of firing rate changes across seizure. 
medRxiv preprint doi: https://doi.org/10.1101/2020.10.09.20204206; this version posted October 20, 2020. The copyright holder for this preprint

(which was not certified by peer review) is the author/funder, who has granted medRxiv a license to display the preprint in perpetuity.

It is made available under a CC-BY-NC-ND 4.0 International license .

a. LFP in Patient $C$ indicating seizure as split into 8 equal time divisions for analysis of unit isolation quality across duration of seizure.

b. Bar graph shows firing rate in 1 second bins of best-isolated example RS unit (green) in Patient C. Dotted red line indicates threshold used to determine best-isolated units using the dynamic $L_{\text {ratio }}$ measure (see Methods) in each time division of seizure. Line plot indicates dynamic $L_{\text {ratio }}$ in each division and shows large separation of example FS unit from noise in feature space used for clustering throughout the seizure (note log scale).

c. Line plot showing average spike amplitude (dark green) and individual spike amplitudes (light green) of example RS unit over course of seizure in Patient $C$. Note that even as amplitude decreases the unit remains well-isolated from noise as quantified by dynamic $L_{\text {ratio }}$ across seizure.

d. Time-voltage histogram of all threshold crossings assigned to this example RS unit (green, Upper) and to noise (red, Lower) in eight divisions of seizure in Patient C. Shows unit waveforms are visually distinguishable from threshold crossings assigned as noise across seizure. 
medRxiv preprint doi: https://doi.org/10.1101/2020.10.09.20204206; this version posted October 20, 2020. The copyright holder for this preprint (which was not certified by peer review) is the author/funder, who has granted medRxiv a license to display the preprint in perpetuity. It is made available under a CC-BY-NC-ND 4.0 International license .
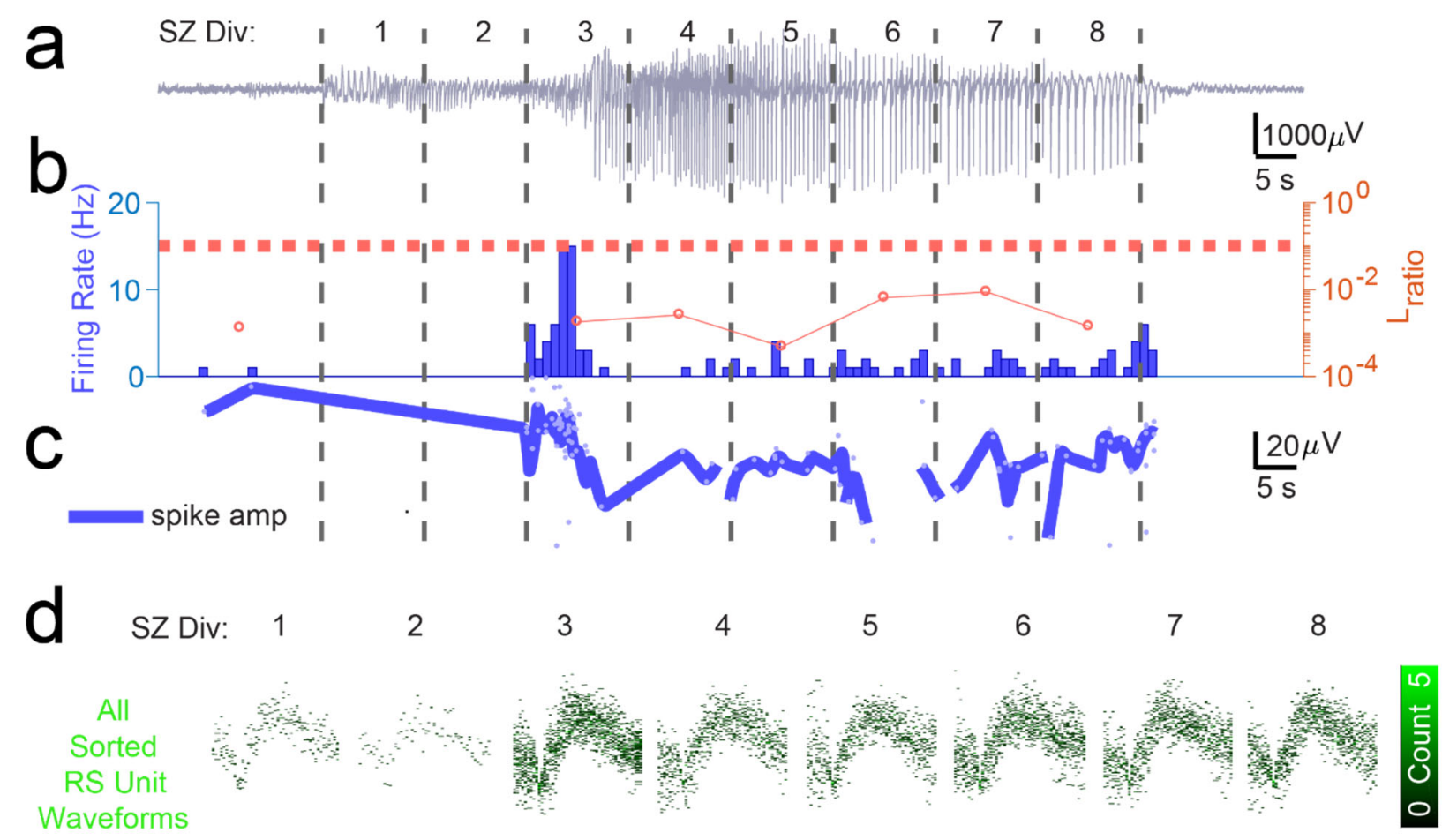

All

\section{Sorted}

FS Unit

Waveforms

$\frac{20}{0.6 \mathrm{~ms}}$

All

Unsorted

Noise

Waveforms
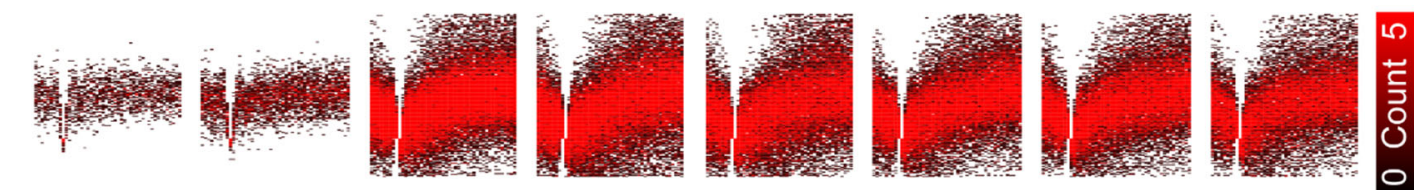
medRxiv preprint doi: https://doi.org/10.1101/2020.10.09.20204206; this version posted October 20, 2020. The copyright holder for this preprint (which was not certified by peer review) is the author/funder, who has granted medRxiv a license to display the preprint in perpetuity.

It is made available under a CC-BY-NC-ND 4.0 International license.

Extended Data Figure 6: Cluster isolation quality assessment suggests RS and FS units on same channel are well-isolatable across seizure despite changing unit amplitude and noise structure, allowing analysis of firing rate changes across seizure for multiple patients.

a. LFP in Patient $B$ indicating seizure as split into 8 equal time divisions for analysis of unit isolation quality across duration of seizure.

b. Bar graph shows firing rate in 1 second bins of best-isolated example FS unit (blue) in Patient B. Dotted red line indicates threshold used to determine best-isolated units using the dynamic $L_{\text {ratio }}$ measure (see Methods) in each time division of seizure. Line plot indicates dynamic $L_{\text {ratio }}$ in each division and shows large separation of example FS unit from noise in feature space used for clustering throughout the seizure (note log scale).

c. Line plot showing average spike amplitude (dark blue) and individual spike amplitudes (light blue) of example FS unit over course of seizure in Patient B. Note that even as amplitude decreases the unit remains well-isolated from noise as quantified by dynamic Lratio across seizure.

d. Time-voltage histogram of all threshold crossings assigned to example FS unit (blue, Middle), RS unit on same channel (green, Upper), and to noise (red, Lower) in eight divisions of seizure in Patient B. Shows unit waveforms are visually distinguishable from threshold crossings assigned as noise and as other units across seizure. 


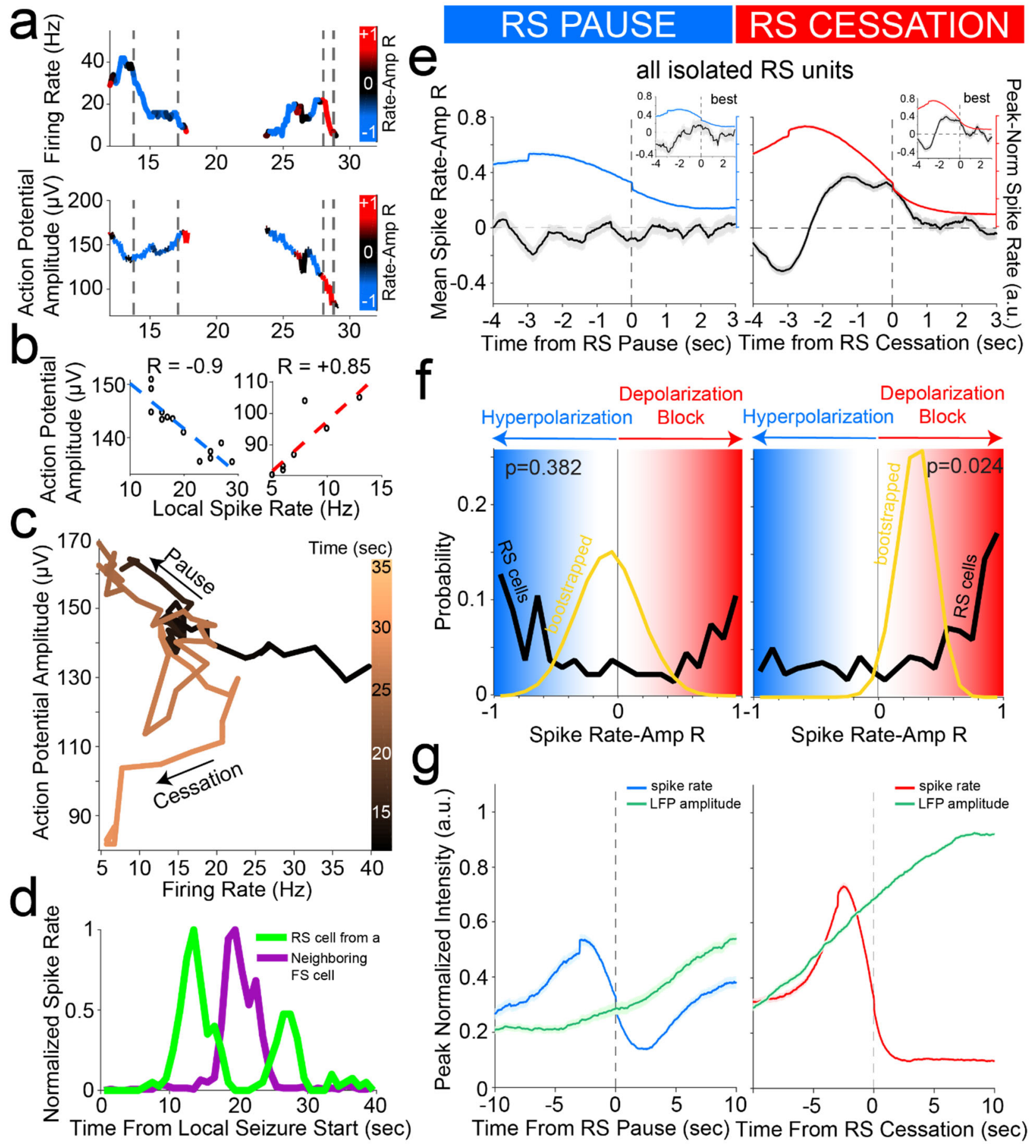

Extended Data Figure 7: Cessation of individual RS unit activity is consistently associated with inferred membrane potential signatures of depolarization block, despite prior pauses

a. Firing rate (upper) and trough-to-peak spike amplitude (lower) of example RS unit in Patient A, color-coded by the local correlation between spike rate and amplitude (in 1 second time bins) as an extracellular proxy for membrane potential trajectory and subthreshold input history. Dotted lines indicate starts and ends of two time periods of firing rate suppression characterized by different membrane potential signatures further characterized in (B), namely a negative correlation regime corresponding to inhibition followed by a positive correlation regime 
corresponding to over-excitation ending in firing rate cessation putatively though depolarization block.

b. Example of negative correlation (left) between local spike rate and amplitude in first time period indicated by dotted lines in $(A)$ and example of positive correlation (right) between local spike rate and amplitude in second time period indicated by dotted lines in (A). Least squares linear fit indicated in dotted lines following color scheme in $(A)$ with Pearson's correlation coefficient indicated above each plot.

c. Trajectory of unit activity over time during seizure in local spike rate vs spike amplitude space, with increasing time indicated by increasingly lighter copper color. The first time period of firing rate reduction in dotted lines in $(A)$ is indicated with an arrow as "Pause" and the second time period of firing rate reduction in dotted lines in $(A)$ is indicated with an arrow as "Cessation."

d. Firing rate of unit from $(\mathrm{A})$ with neighboring $\mathrm{FS}$ unit firing rate overlaid, giving further evidence that first period of firing rate suppression corresponds to inhibition from local FS units while second period of firing rate suppression does not correspond to inhibition from local FS units.

e. Unit cessation-triggered population average of the time course of novel membrane potential regime measure, i.e. the correlation coefficient relating spiking amplitude and rate in a local time window, around the two significant descents in firing rate (below $30 \%$ of peak rate) that occur in sequence during seizure. These are designated as pause (left panel) and cessation (right panel). Left panel shows population average firing rate (blue) and inferred membrane potential regime (black) aligned according to the time of pause in each unit, for all RS units displaying a pause $(n=176)$, with inset showing average for best-isolated RS units displaying a pause $(n=41)$. Right panel shows population average firing rate (red) and inferred membrane potential regime (black) aligned according to the cessation time of each unit, for all RS units meeting cessation criteria $(n=379)$, with inset showing average for best-isolated RS units $(n=111)$.

f. Probability distribution of membrane potential regime measure (spike rate-amplitude correlation; black line) at the time of pause (left panel) for RS unit pausing subpopulation $(n=176)$ with sample mean distribution (gold line; resampling size $n=10, N_{\text {bootstrap }}=50,000$ ) showing a bimodal distribution of correlation coefficients near +1 and -1 , i.e. in the hyperpolarized membrane potential regime (blue) or in the highly depolarized regime (red). The population distribution of inferred membrane potential regime is also shown at the time of cessation (right panel) for the RS unit population meeting cessation criteria $(n=379)$ with sample mean distribution (gold line; resampling size $n=10, N_{\text {bootstrap }}=50,000$ ) showing the mean correlation to be significantly above zero, i.e. in the highly depolarized membrane potential regime (red). This is indicative of widespread depolarization block occurring across RS population at the time of cessation.

g. Unit cessation-triggered population average of the time course of same-electrode LFP amplitude around unit activity pause (left panel) and cessation (right panel). In particular, left panel shows population average firing rate (blue) and LFP amplitude (black) aligned according to the time of pause in each unit, for all RS units displaying a pause $(n=176)$. Right panel shows population average firing rate (red) and LFP amplitude (black) aligned according to the time of cessation in each unit, for all RS units $(n=379)$. 


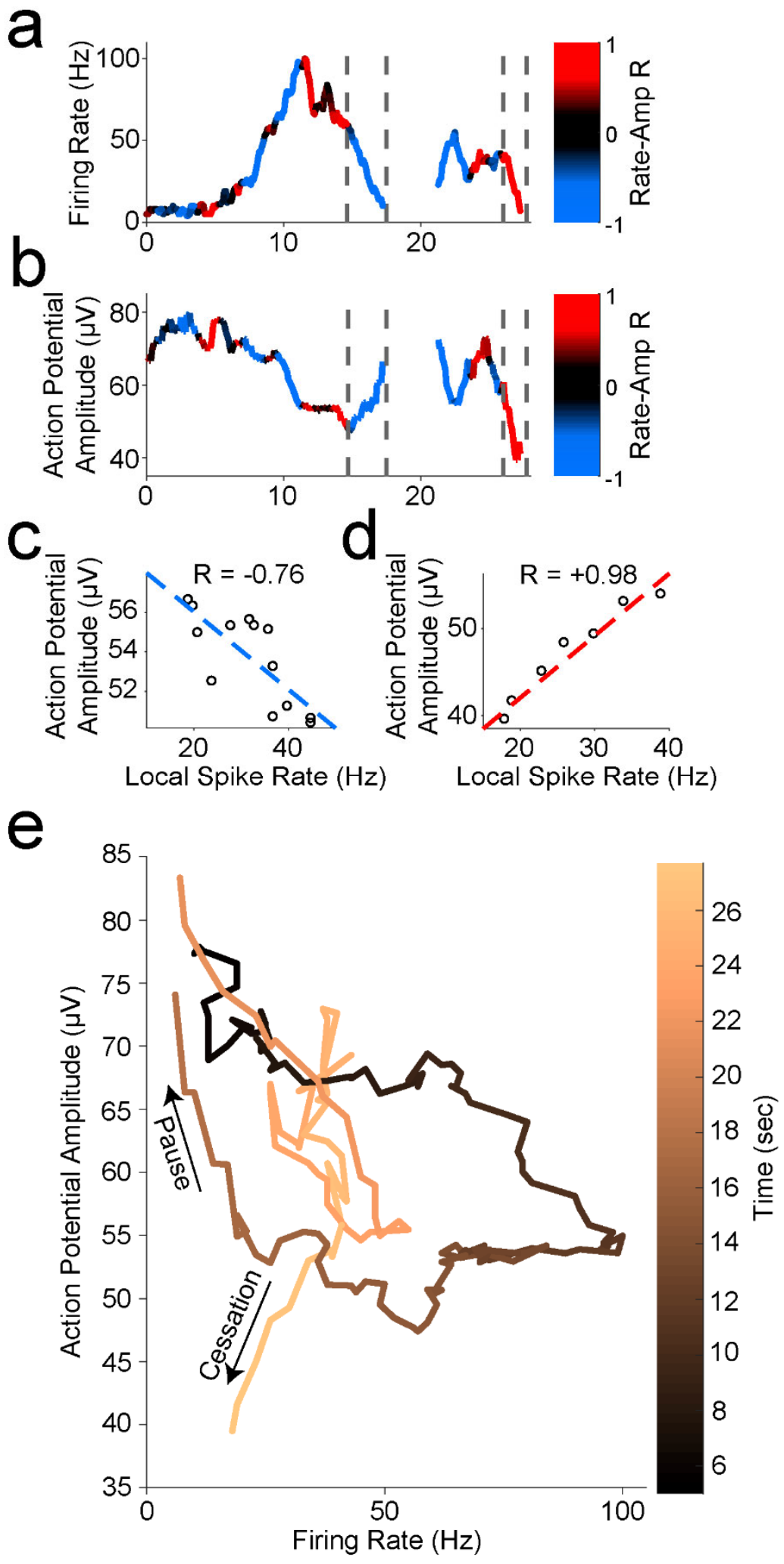


medRxiv preprint doi: https://doi.org/10.1101/2020.10.09.20204206; this version posted October 20, 2020. The copyright holder for this preprint (which was not certified by peer review) is the author/funder, who has granted medRxiv a license to display the preprint in perpetuity.

Extended Data Figure 8: Seizure progression is consistently associated with extracellular signs of depolarization block preceded by inhibition in single units.

a. Firing rate (upper) and trough-to-peak spike amplitude (lower) of another example FS unit in Patient A, color-coded by the local correlation between spike rate and amplitude (in 1 second time bins) as an extracellular proxy for membrane potential and subthreshold input history. Dotted lines indicate starts and ends of two time periods of firing rate suppression characterized by different membrane potential signatures further characterized in (B), namely a negative correlation regime corresponding to inhibition followed by a positive correlation regime corresponding to over-excitation ending in firing rate cessation putatively though depolarization block.

b. Example of negative correlation (left) between local spike rate and amplitude in first time period indicated by dotted lines in $(A)$ and example of positive correlation (right) between local spike rate and amplitude in second time period indicated by dotted lines in (A). Least squares linear fit indicated in dotted lines following color scheme in (A) with Pearson's correlation coefficient indicated above each plot.

c. Trajectory of unit activity over time during seizure in local spike rate vs spike amplitude space, with increasing time indicated by increasingly lighter copper color. The first time period of firing rate reduction in dotted lines in $(A)$ is indicated with an arrow as "Pause" and the second time period of firing rate reduction in dotted lines in $(A)$ is indicated with an arrow as "Cessation." 


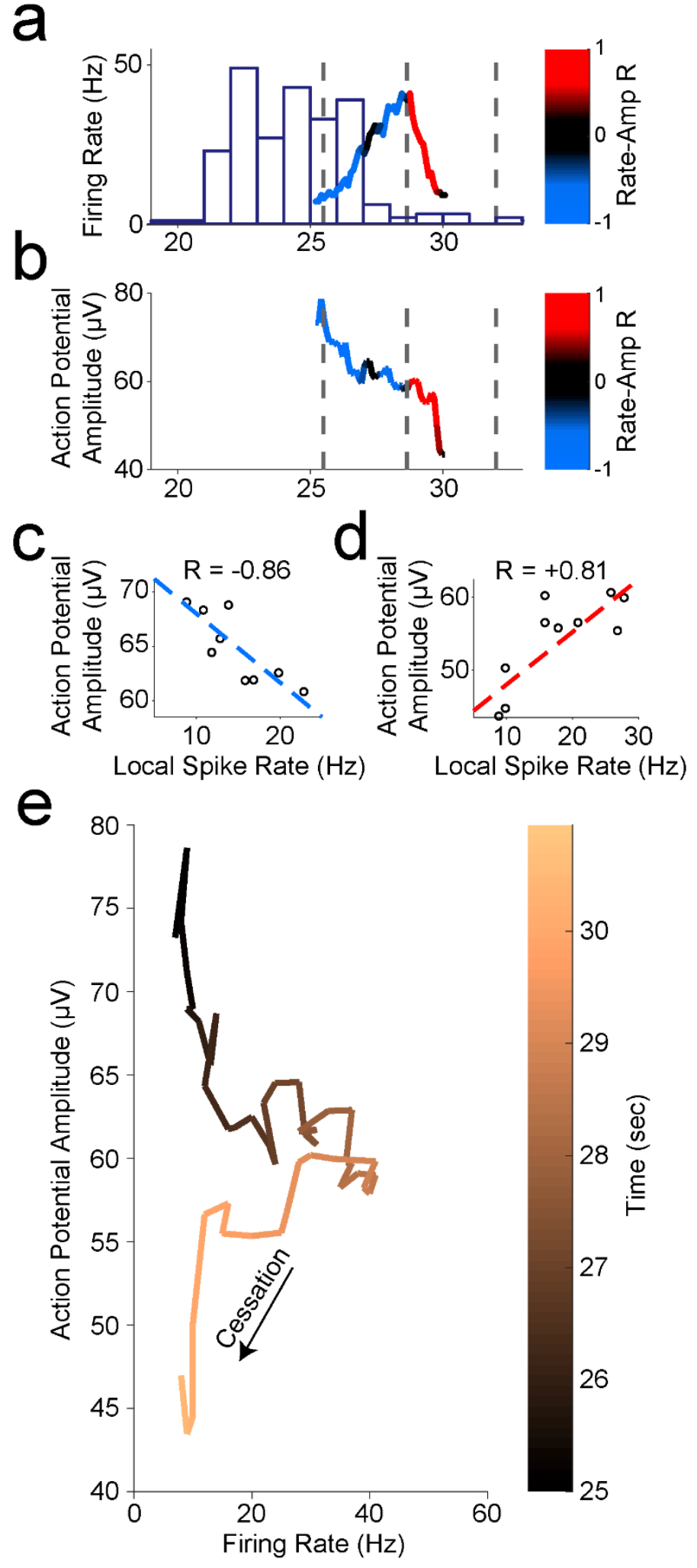


medRxiv preprint doi: https://doi.org/10.1101/2020.10.09.20204206; this version posted October 20, 2020. The copyright holder for this preprint (which was not certified by peer review) is the author/funder, who has granted medRxiv a license to display the preprint in perpetuity.

Extended Data Figure 9: Seizure progression is consistently associated with extracellular signs of depolarization block preceded by inhibition in single units.

a. Firing rate (upper) and trough-to-peak spike amplitude (lower) of another example RS unit in Patient A, color-coded by the local correlation between spike rate and amplitude (in 1 second time bins) as an extracellular proxy for membrane potential and subthreshold input history. Firing rate of local FS unit is overlaid as purple histogram. Dotted lines indicate start and end times of two time periods of firing rate suppression characterized by different membrane potential signatures further characterized in (B), namely a negative correlation regime corresponding to inhibition followed by a positive correlation regime corresponding to over-excitation ending in firing rate cessation putatively though depolarization block.

1031

1032

1033

1034

1035

b. Example of negative correlation (left) between local spike rate and amplitude in first time period indicated by dotted lines in $(A)$ and example of positive correlation (right) between local spike rate and amplitude in second time period indicated by dotted lines in (A). Least squares linear fit indicated in dotted lines following color scheme in $(A)$ with Pearson's correlation coefficient indicated above each plot.

c. Trajectory of unit activity over time during seizure in local spike rate vs spike amplitude space, with increasing time indicated by increasingly lighter copper color. RS unit is released from inhibition shortly following the cessation of activity in local FS unit as indicated by increasing firing rate with decreasing amplitude but then enters regime of over-excitation indicated by decreasing firing rate with decreasing amplitude at trajectory "corner" corresponding to a spiking rate of 40 $\mathrm{Hz}$, until the unit ceases to fire likely due to depolarization block given these indicators of membrane potential history. 
medRxiv preprint doi: https://doi.org/10.1101/2020.10.09.20204206; this version posted October 20, 2020. The copyright holder for this preprint (which was not certified by peer review) is the author/funder, who has granted medRxiv a license to display the preprint in perpetuity.

1064

1065

1066

1067

1068

1069

1070

1071

1072

1073

1074

1075

1076

1077

1078

1079

1080

1081

1082

1083

1084

1085

1086

1087

1088

1089

1090

1091

1092

1093

1094

1095

1096

1097

1098

1099

1100

1101

1102

1103

1104

1105

1106

1107

\section{REFERENCES}

1. Annegers, J. F. The Treatment of Epilepsy: Principles and Practice. (Third Edition). in The Treatment of Epilepsy: Principles and PRac (ed. Wyllie, E.) 131138 (Wiley, 2001). doi:10.1002/hup.372

2. Thurman, D. J. et al. Standards for epidemiologic studies and surveillance of epilepsy. Epilepsia 52, 2-26 (2011).

3. Žiburkus, J., Cressman, J. R. \& Schiff, S. J. Seizures as imbalanced up states: excitatory and inhibitory conductances during seizure-like events. J. Neurophysiol. 109, 1296-1306 (2013).

4. Farrell, J. S., Nguyen, Q.-A. \& Soltesz, I. Review Resolving the Micro-Macro Disconnect to Address Core Features of Seizure Networks. Neuron 101, 10161028 (2019).

5. Elahian, B. et al. Low-voltage fast seizures in humans begin with increased interneuron firing. Ann. Neurol. 84, 588-600 (2018).

6. Weiss, S. A. et al. Ictal onset patterns of local field potentials, high frequency oscillations, and unit activity in human mesial temporal lobe epilepsy. Epilepsia 57, 111-121 (2016).

7. Schwartzkroin, P. A. \& Prince, D. A. Changes in excitatory and inhibitory synaptic potentials leading to epileptogenic activity. Brain Res. 183, 61-77 (1980).

8. Gutnick, M. J., Connors, B. W. \& Prince, D. A. Mechanisms of neocortical epileptogenesis in vitro. J. Neurophysiol. 48, 1321-1335 (1982).

9. Prince, D. A. \& Connors, B. W. Mechanisms of epileptogenesis in cortical structures. Ann. Neurol. 16, S59-S64 (1984).

10. McCormick, D. A., Connors, B. W., Lighthall, J. W. \& Prince, D. A. Comparative electrophysiology of pyramidal and sparsely spiny stellate neurons of the neocortex. J. Neurophysiol. 54, 782-806 (1985).

11. Chagnac-Amitai, Y. \& Connors, B. W. Horizontal spread of synchronized activity in neocortex and its control by GABA-mediated inhibition. J. Neurophysiol. 61, 747-758 (1989).

12. Ziburkus, J., Cressman, J. R., Barreto, E. \& Schiff, S. J. Interneuron and pyramidal cell interplay during in vitro seizure-like events. J. Neurophysiol. 95, 3948-3954 (2006).

13. Trevelyan, A. J. \& Schevon, C. A. How inhibition influences seizure propagation. Neuropharmacology 69, 45-54 (2013).

14. Karlócai, M. R. et al. Physiological sharp wave-ripples and interictal events in vitro: what's the difference? Brain 137, 463-85 (2014).

15. Pavlov, I. \& Walker, M. C. Tonic GABAA receptor-mediated signalling in temporal lobe epilepsy. Neuropharmacology 69, 55-61 (2013).

16. Avoli, M. \& de Curtis, M. GABAergic synchronization in the limbic system and its role in the generation of epileptiform activity. Progress in Neurobiology 95, 104132 (2011).

17. Cope, D. W. et al. Enhanced tonic GABA A inhibition in typical absence epilepsy. Nat. Med. 15, 1392-1398 (2009). 
medRxiv preprint doi: https://doi.org/10.1101/2020.10.09.20204206; this version posted October 20, 2020. The copyright holder for this preprint (which was not certified by peer review) is the author/funder, who has granted medRxiv a license to display the preprint in perpetuity. It is made available under a CC-BY-NC-ND 4.0 International license .

1108

18. Neumann, A. R. et al. Involvement of fast-spiking cells in ictal sequences during spontaneous seizures in rats with chronic temporal lobe epilepsy. Brain 140, 2355-2369 (2017).

19. Sessolo, M. et al. Parvalbumin-positive inhibitory interneurons oppose propagation but favor generation of focal epileptiform activity. J. Neurosci. 35 , 9544-9557 (2015).

20. Lévesque, M., Herrington, R., Hamidi, S. \& Avoli, M. Interneurons spark seizurelike activity in the entorhinal cortex. Neurobiol. Dis. 87, 91-101 (2016).

21. Khoshkhoo, S., Vogt, D. \& Sohal, V. S. Dynamic, Cell-Type-Specific Roles for GABAergic Interneurons in a Mouse Model of Optogenetically Inducible Seizures. Neuron 93, 291-298 (2017).

22. Xu, H., Jeong, H. Y., Tremblay, R. \& Rudy, B. Neocortical SomatostatinExpressing GABAergic Interneurons Disinhibit the Thalamorecipient Layer 4. Neuron 77, 155-167 (2013).

23. Buckmaster, P. S., Jongen-Rêlo, A. L., Davari, S. B. \& Wong, E. H. Testing the disinhibition hypothesis of epileptogenesis in vivo and during spontaneous seizures. J. Neurosci. 20, 6232-40 (2000).

24. Miri, M. L., Vinck, M., Pant, R. \& Cardin, J. A. Altered hippocampal interneuron activity precedes ictal onset. Elife 7, (2018).

25. Cammarota, M., Losi, G., Chiavegato, A., Zonta, M. \& Carmignoto, G. Fast spiking interneuron control of seizure propagation in a cortical slice model of focal epilepsy. J. Physiol. 591, 807-822 (2013).

26. Petersen, C. C. H. Whole-Cell Recording of Neuronal Membrane Potential during Behavior. Neuron 95, 1266-1281 (2017).

27. Nowak, L. G., Azouz, R., Sanchez-Vives, M. V., Gray, C. M. \& McCormick, D. A. Electrophysiological classes of cat primary visual cortical neurons in vivo as revealed by quantitative analyses. J. Neurophysiol. 89, 1541-1566 (2003).

28. Cardin, J. A. et al. Driving fast-spiking cells induces gamma rhythm and controls sensory responses. Nature 459, 663-667 (2009).

29. Rudy, B., Fishell, G., Lee, S. H. \& Hjerling-Leffler, J. Three groups of interneurons account for nearly $100 \%$ of neocortical GABAergic neurons. Dev. Neurobiol. 71, 45-61 (2011).

30. Connors, B. W., Pinto, D. J. \& Telfeian, A. E. Local pathways of seizure propagation in neocortex. Int. Rev. Neurobiol. 45, 527-46 (2001).

31. Merricks, E. M. et al. Single unit action potentials in humans and the effect of seizure activity. Brain 138, 2891-906 (2015).

32. Schevon, C. A. et al. Evidence of an inhibitory restraint of seizure activity in humans. Nat. Commun. 3, 1060 (2012).

33. Sabolek, H. R. et al. A candidate mechanism underlying the variance of interictal spike propagation. J. Neurosci. 32, 3009-3021 (2012).

34. Chervin, R. D., Pierce, P. A. \& Connors, B. W. Periodicity and directionality in the propagation of epileptiform discharges across neocortex. J. Neurophysiol. 60, 1695-1713 (1988).

35. Wong, B. Y. \& Prince, D. A. The lateral spread of ictal discharges in neocortical brain slices. Epilepsy Res. 7, 29-39

36. Golomb, D. \& Amitai, Y. Propagating neuronal discharges in neocortical slices: 
medRxiv preprint doi: https://doi.org/10.1101/2020.10.09.20204206; this version posted October 20, 2020. The copyright holder for this preprint (which was not certified by peer review) is the author/funder, who has granted medRxiv a license to display the preprint in perpetuity.

It is made available under a CC-BY-NC-ND 4.0 International license .

1154

1155

1156

1157

1158

1159

1160

1161

1162

1163

1164

1165

1166

1167

1168

1169

1170

1171

1172

1173

1174

1175

1176

1177

1178

1179

1180

1181

1182

1183

1184

1185

1186

1187

1188

1189

1190

1191

1192

1193

1194

1195

1196

1197

1198

1199

Computational and experimental study. J. Neurophysiol. 78, 1199-1211 (1997).

37. Liou, J. Y. et al. A model for focal seizure onset, propagation, evolution, and progression. Elife 9, (2020).

38. Martina, M., Schultz, J. H., Ehmke, H., Monyer, H. \& Jonas, P. Functional and molecular differences between voltage-gated $\mathrm{K}+$ channels of fast-spiking interneurons and pyramidal neurons of rat hippocampus. J. Neurosci. 18, 81118125 (1998).

39. Rudy, B. \& McBain, C. J. Kv3 channels: Voltage-gated K+ channels designed for high-frequency repetitive firing. Trends in Neurosciences 24, 517-526 (2001).

40. Lien, C. C. \& Jonas, P. Kv3 potassium conductance is necessary and kinetically optimized for high-frequency action potential generation in hippocampal interneurons. J. Neurosci. 23, 2058-2068 (2003).

41. Somjen, G. G. Ions in the brain : normal function, seizures, and stroke. (Oxford University Press, 2004).

42. Fröhlich, F., Bazhenov, M., Iragui-Madoz, V. \& Sejnowski, T. J. Reviews: Potassium dynamics in the epileptic cortex: New insights on an old topic. Neuroscientist 14, 422-433 (2008).

43. Cruikshank, S. J., Lewis, T. J. \& Connors, B. W. Synaptic basis for intense thalamocortical activation of feedforward inhibitory cells in neocortex. Nat. Neurosci. 10, 462-468 (2007).

44. Pouille, F. \& Scanziani, M. Routing of spike series by dynamic circuits in the hippocampus. Nature 429, 717-723 (2004).

45. Markram, H. et al. Interneurons of the neocortical inhibitory system. Nature Reviews Neuroscience 5, 793-807 (2004).

46. Kawaguchi, Y. Physiological subgroups of nonpyramidal cells with specific morphological characteristics in layer II/III of rat frontal cortex. J. Neurosci. 15, 2638-2655 (1995).

47. Kramer, M. A. et al. Human seizures self-terminate across spatial scales via a critical transition. Proc. Natl. Acad. Sci. U. S. A. 109, 21116-21121 (2012).

48. Beverlin, B., Kakalios, J., Nykamp, D. \& Netoff, T. I. Dynamical changes in neurons during seizures determine tonic to clonic shift. J. Comput. Neurosci. 33, 41-51 (2012).

49. Fröhlich, F., Sejnowski, T. J. \& Bazhenov, M. Network bistability mediates spontaneous transitions between normal and pathological brain states. J. Neurosci. 30, 10734-10743 (2010).

50. Blumenfeld, $\mathrm{H}$. Cellular and network mechanisms of spike-wave seizures. Epilepsia 46, 21-33 (2005).

51. Berényi, A., Belluscio, M., Mao, D. \& Buzsáki, G. Closed-loop control of epilepsy by transcranial electrical stimulation. Science (80-. ). 337, 735-737 (2012).

52. Wykes, R. C. et al. Epilepsy: Optogenetic and potassium channel gene therapy in a rodent model of focal neocortical epilepsy. Sci. Transl. Med. 4, (2012).

53. Paz, J. T. et al. Closed-loop optogenetic control of thalamus as a tool for interrupting seizures after cortical injury. Nat. Neurosci. 16, 64-70 (2013).

54. Krook-Magnuson, E., Armstrong, C., Oijala, M. \& Soltesz, I. On-demand optogenetic control of spontaneous seizures in temporal lobe epilepsy. Nat. Commun. 4, 1-8 (2013). 
1200 55. Sukhotinsky, I. et al. Optogenetic Delay of Status Epilepticus Onset in an In Vivo Rodent Epilepsy Model. PLoS One 8, (2013).

56. Bikson, M., Hahn, P. J., Fox, J. E. \& Jefferys, J. G. R. Depolarization block of neurons during maintenance of electrographic seizures. J. Neurophysiol. $\mathbf{9 0}$, 2402-2408 (2003).

57. Hoffman, D. A., Magee, J. C., Colbert, C. M. \& Johnston, D. K+ channel regulation of signal propagation in dendrites of hippocampal pyramidal neurons. Nature 387, 869-875 (1997).

58. Schmitzer-Torbert, N., Jackson, J., Henze, D., Harris, K., \& Redish, A. D. Quantitative measures of cluster quality for use in extracellular recordings. Neuroscience 131, 1-11 (2005).

59. Magloire, V., Mercier, M. S., Kullmann, D. M., \& Pavlov, I. GABAergic interneurons in seizures: Investigating causality with optogenetics. The Neuroscientist 25, 344-358 (2019).

60. De Polavieja, G. G., Harsch, A., Kleppe, I., Robinson, H. P. C. \& Juusola, M. Stimulus history reliably shapes action potential waveforms of cortical neurons. J. Neurosci. 25, 5657-5665 (2005). 